\title{
Screening Tools as a Predictor of Injury in Dance: Systematic Literature Review and Meta-analysis
}

\author{
Ross Armstrong ${ }^{1^{*}}$ (D) and Nicola Relph ${ }^{2}$
}

\begin{abstract}
Background: Dance involves movements of complexity and physical intensity which result in stress on the body. As a consequence, dancers are at risk of injury which can impact on their well-being. Screening tools are used for injury prevention to identify those dancers at risk of injury. The aim of this study was to investigate which screening tools can predict injury in dancers, encompassing all dance genres, levels and ages.

Methods: An electronic search of seven databases from their inception to December 2017 was conducted. The databases were the Allied and Complementary Medicine Database (AMED), CINAHL, eBOOK Collection (EBSCOhost), MEDLINE, Cochrane Database of Systematic Reviews, SPORTDiscus and PEDro: the Physiotherapy Evidence Base. The following search terms were used: (i) Dance AND injury AND Screening, (ii) Screening AND dance and (iii) Musculoskeletal AND Screening AND Dance. Studies were assessed using a 20-point scoring tool, and eligible studies were included in a meta-analysis.
\end{abstract}

Results: The mean methodological quality score was 12.2 points. Injured dancers had a significantly higher compensated turnout range of motion than non-injured dancers: pooled mean difference of compensated turnout $\left(23.29^{\circ} ; 95 \% \mathrm{Cl} 14.85-31.73 ; P<0.00001 ; P^{2}=0 \%\right)$. Injured dancers had significantly greater functional turnout range of motion when compared to non-injured dancers: pooled mean difference of functional turnout $\left(14.08^{\circ} ; 95 \% \mathrm{Cl} 7.09-21.07 ; P<0.0001 ; P^{2}=0 \%\right)$. There also some evidence for use of hip range of motion as a predictor of dance injury.

Conclusions: Some evidence exists for the potential use of dance-specific positions as a predictor of injury. A number of studies were limited by a lack of prospective injury design, injury definition and self-reporting of injury.

Keywords: Screening tool, Dancers, Musculoskeletal, Injury prevention, Injury risk, Compensated turnout, Functional turnout, Hip range of motion

\section{Key Points}

- Functional turnout and compensated turnout range of motion may predict injury in dancers.

- Some evidence exists for measurement of hip range of motion as a predictor of injury.

- There is a need for prospective studies that define the injury and have a physical therapist/

\footnotetext{
*Correspondence: armsross@edgehill.ac.uk

'Sports Injuries Research Group, Department of Sport and Physical Activity,

Edge Hill University, Ormskirk, Lancashire L39 4QP, England

Full list of author information is available at the end of the article
}

physiotherapist and/or doctor providing the diagnosis of the injury.

\section{Background}

Dance is an intermittent exercise associated with short sets of explosive movements that require balance, athleticism and artistry [1], indicative of the movement complexity and intensity. Therefore, dancers require physical attributes including strength, speed, power, agility, cardiovascular endurance, flexibility, coordination and balance to meet the performance demands. Dance places considerable stress on the body; vertical ground reaction forces increase with the intensity of the dance 
routine [2, 3], and mechanical loading increases with movement difficulty [4]. These high forces generated during dance combined with movements that often exceed normal anatomical range can potentially result in injury [5].

Dance injury rates between 0.62 and 5.6 injuries per 1000-h dance have been reported [5-8]. The majority of injuries occur in the lower limb with overuse and foot and ankle injuries most prevalent [5-8]. The demands of dance are varied, for example, ballet requires partner lifting, tap dancing uses the lower extremity as a percussion tool and upper limb weight bearing is required in breaking. Previous systematic reviews $[9,10]$ have highlighted that dance has a high risk of injury regardless of genre and level. One possible cause is repetitive poor movement patterns which may result in micro-trauma and subsequent injury [11]. The negative impact that injury can have on a dancer's health and well-being means that injury prevention practices are crucial. These injury prevention practices require collaboration within the Sports Medicine Team which may include physiotherapists/physical therapists, doctors, rheumatologists, nurse practitioners, strength and conditioning coaches and sports scientists.

Screening tools are a vital component of injury prevention that may identify athletes that are at risk of injury development [12-16]. Tools include scales that grade movements such as the Functional Movement Screen $[17,18]$, the Star Excursion Balance Test [19] and the Beighton Score [20] or the recording of specific joint measurements such as range of motion (ROM). The development of screening tools often utilise the Van Mechelen model of injury prevention [21] and injury audit which can assist in the development of injury prevention programmes.

The determination and implementation of effective screening tools could have positive physical and psychological impact on dancers by allowing participation with reduced injury risk. There is an abundance of literature considering screening tools in dance; however, the findings of this literature have yet to be synthesised in a systematic review and meta-analysis. The current systematic literature review is the first to investigate which screening tools can predict injury in dancers and encompasses all dance genres, levels and ages. A meta-analysis is also completed to synthesise similar data sets where appropriate.

\section{Methods}

\section{Literature Search}

A systematic literature search was conducted to obtain articles concerning screening tools that can potentially predict injury in dancers from their inception of seven databases until December 2017. The databases were the Allied and Complementary Medicine Database (AMED), CINAHL, eBOOK Collection (EBSCOhost), MEDLINE, Cochrane Database of Systematic Reviews, SPORTDiscus and PEDro: the Physiotherapy Evidence Base. A combination of the following search terms was used: (i) Dance AND injury AND Screening, (ii) Screening AND dance and (iii) Musculoskeletal AND Screening AND Dance. These terms were searched in all text, abstract, title and subject terms. Reference lists of acquired articles were screened to find additional articles, and duplicates were removed. Only peer-reviewed articles in the English language were considered.

\section{Study Selection}

The titles and abstracts of the search returned articles were reviewed by the first author (RA) to identify potential relevance using a two-stage process. The first stage involved the classification of articles as relevant, potentially relevant or irrelevant. During this stage, irrelevant articles were excluded, and articles that met the inclusion were retained for further analysis. The second stage involved the review of the full text of relevant and potentially relevant articles by two reviewers (RA and NR). Both reviewers formulated comments regarding the suitability of articles using the checklist of five inclusion criteria and then met to determine final inclusion via reviewing these comments. Any potential disagreements regarding the inclusion were referred to a third reviewer to determine final inclusion. Studies were included if they were (i) full text, (ii) in the English language, (iii) used a screening tool, (iv) the population was dancers and (v) injury occurrence was reported either retrospectively or prospectively. Studies that utilised equipment such as isokinetic dynamometers, bone mineral density scanners and foot scanners were excluded as they were deemed to be laboratory-based and limited in the practical application of dance injury screening. Studies that used screening to provide a treatment intervention to dancers were excluded.

\section{Data Extraction}

Two reviewers (RA and NR) independently extracted data from each article. The following information was extracted if available: study design (prospective or retrospective), level of evidence, location of testing, inclusion and exclusion criteria, subject characteristics (age, sex, height, weight); screening tool and/or physical measurements recorded; reliability and validity of screening tool and/or physical measurements and method of injury collection including retrospective/prospective injury collection, definition of injury, individual diagnosing injury, statistical analysis of injury measure, percentage of missing data or withdrawals, outcome measures and identification of confounders.

\section{Methodological Quality}

A previous review of injury screening tools in team sports [22] utilised a 16-point scoring system. This scoring tool was developed from a modified version of the 
Cochrane Group on Screening and Diagnostic Test Methodology (Cochrane methods) [23]. However, limitations in this tool were identified such as reliability analysis; studies that reported reliability using data collected within the study were scored the same as studies which provided reliability values from previous studies. The previous scoring system also failed to acknowledge the importance of providing an injury definition and accurate diagnosis, as highlighted in previous dance injury reviews $[9,10]$. The strength of prospective injury study design in comparison with retrospective design and the need for multivariable analysis to identify injury risk factors has been advocated [9]. Therefore, the authors decided to add four points to the scoring tool including (i) definition of injury provided (1 point), (ii) diagnosis of injury by physical therapist/physiotherapist or doctor (1 point), (iii) the use of regression models or risk measurement (1 point) and (iv) reliability reported for the actual study (1 point).

The maximum score of the modified tool was 20 points. The scoring system is outlined in Table 1 . The level of evidence devised from the Oxford Centre for Evidence-Based Medicine ranged from 1 to 5 , with 1 the lowest and 5 the highest score. With regard to the design of the study, those studies that included both retrospective and prospective injury data collection were awarded 1 point, setting information needed to include the name of the venue and for inclusion and exclusion criteria both had to be stated to score 1 point. The methodological score based on statistical analysis was divided into two separate questions. The study was awarded 1 point if it had included an inferential statistical analysis of any kind. However, the study was awarded an additional point if a regression model or risk measurement had been applied; in the current review, this included linear regression models, logistical regression models, Cox regression models, odds ratio (OR) analysis and relative risk (RR) analysis. This aspect of the methodological quality score would allow differentiation between the studies that consider the injury screening tool predictive capability and those who did not. The studies which considered only the ability of the screening tool to identify the differences between the injured and non-injured groups were not awarded with this additional point.

\section{Data Extraction and Analysis}

Studies that included similar screening tools were considered for inclusion in the meta-analysis. The following data were extracted by one reviewer and cross-checked by the second reviewer: the number of participants, mean screening tool measurement and accompanying standard deviations. It was possible to synthesise the data from three screening tools reported in the included studies, all of which related to turnout. In ballet, turnout refers to the outward rotation of the legs and feet so that the hips are externally rotated and is required to achieve first, second, third, fourth and fifth ballet positions [24]. The following comparisons were possible in the current review:

- Passive hip external rotation range of motion in the injured group vs passive hip external rotation range of motion in the non-injured group.

- Functional turnout (defined as the angle of turnout assumed by a dancer in any of the five basic ballet positions [24]) in the injured group vs function turnout in the non-injured group.

- Compensated turnout (defined as the difference between the first position turnout angle (functional turnout) and the total ROM of passive hip external rotation for both hips [24]) in injured group vs compensated turnout in the non-injured group.

Comparisons were made using a fixed effect model with an inverse variance method and presented as forest plots using Review Manager Software (version 5.3.5). The mean difference between groups measured the effect size. Heterogeneity between comparable trials was tested using the chi-squared test (level of significance set at $P<0.10$ ) and $I^{2}$ percentages (lower than 50\%) [25]. Studies that could not be included in the meta-analysis were analysed using qualitative review.

\section{Results}

\section{Included Studies}

The initial search yielded 1806 studies for review. The title and abstracts of these articles were reviewed and duplicates removed, which resulted in 75 articles requiring further consideration. Assessment of the eligibility of the full text of these articles and the application of inclusion and exclusion criteria meant that 42 articles were included in the systematic review. Figure 1 outlines the search strategy. The assessment of the methodological quality is reported in Table 1 . The mean score was 12.2 points (range 6-17 points). Table 2 reports the characteristics of these studies.

Nineteen studies included ballet dancers [24, 26-43], two studies included contemporary dancers [44, 45], three studies included Irish dancers [46-48] and eight studies included a mixed group of dancers [49-56]. In nine studies, the dance genre was unclear [5, 57-64], and one study used dance degree students but did not state the genre [65]. With regard to the level of dance, nine studies included dancers classified as elite/professional [26-29, 37, 48, 50, 60, 62], seven studies as pre-professional [5, 33, 42, 56-59] and 21 studies as non-elite/non-professional [24, 30-32, 34-36, 38, 39, 44, $45,49,51-55,61,63-65]$. Three studies used a mixed 
Armstrong and Ralph Sports Medicine - Open (2018) 4:33

Page 4 of 28

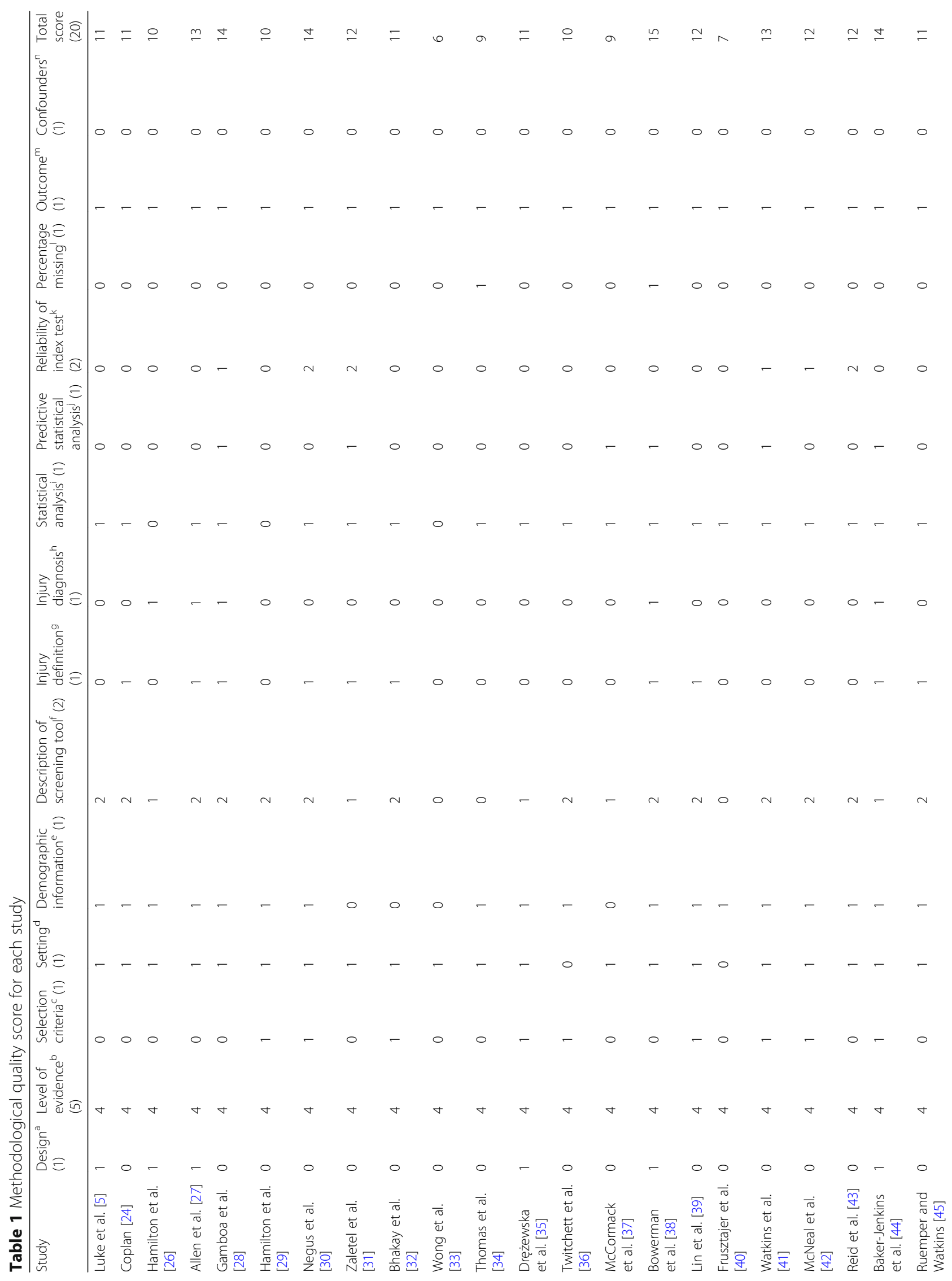


Armstrong and Ralph Sports Medicine - Open (2018) 4:33

Page 5 of 28

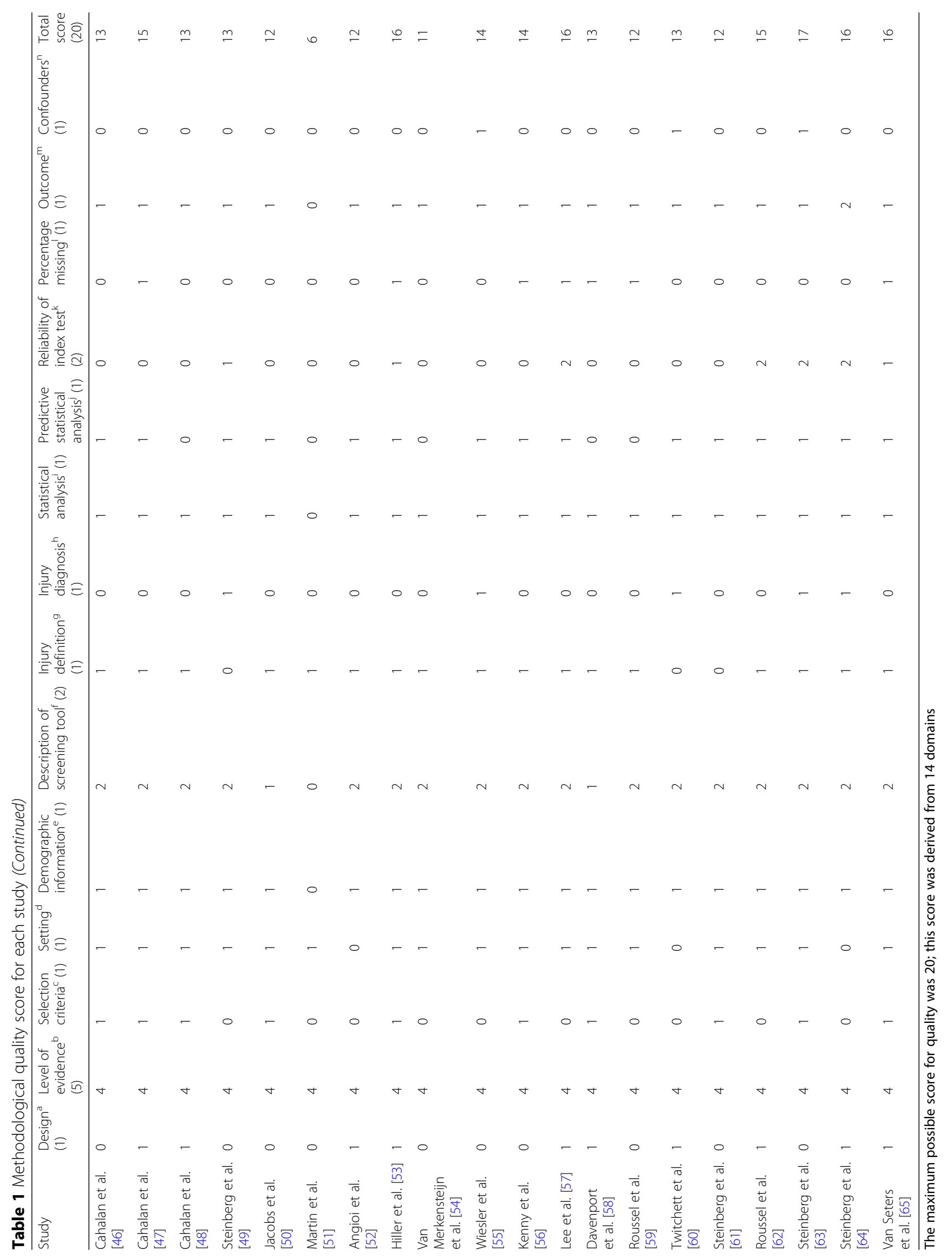




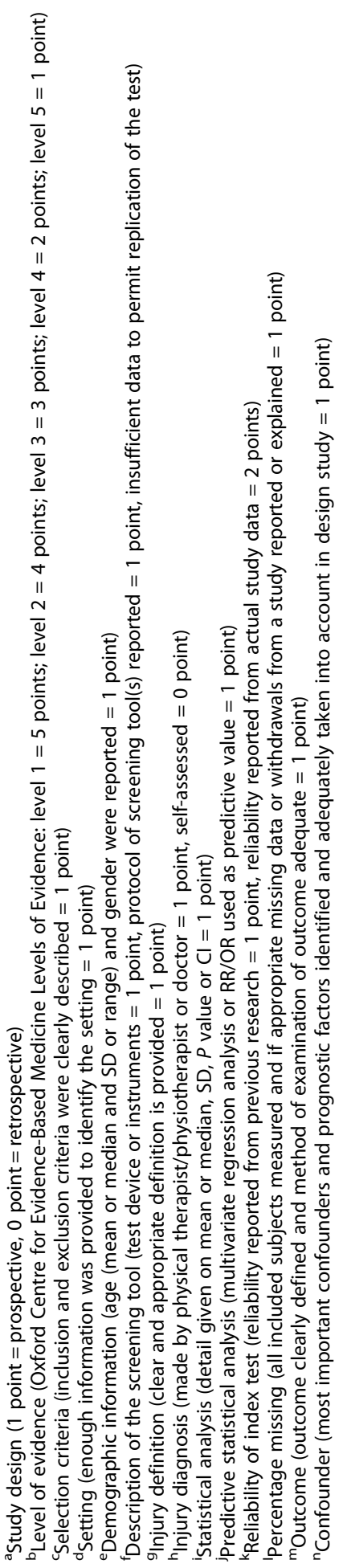




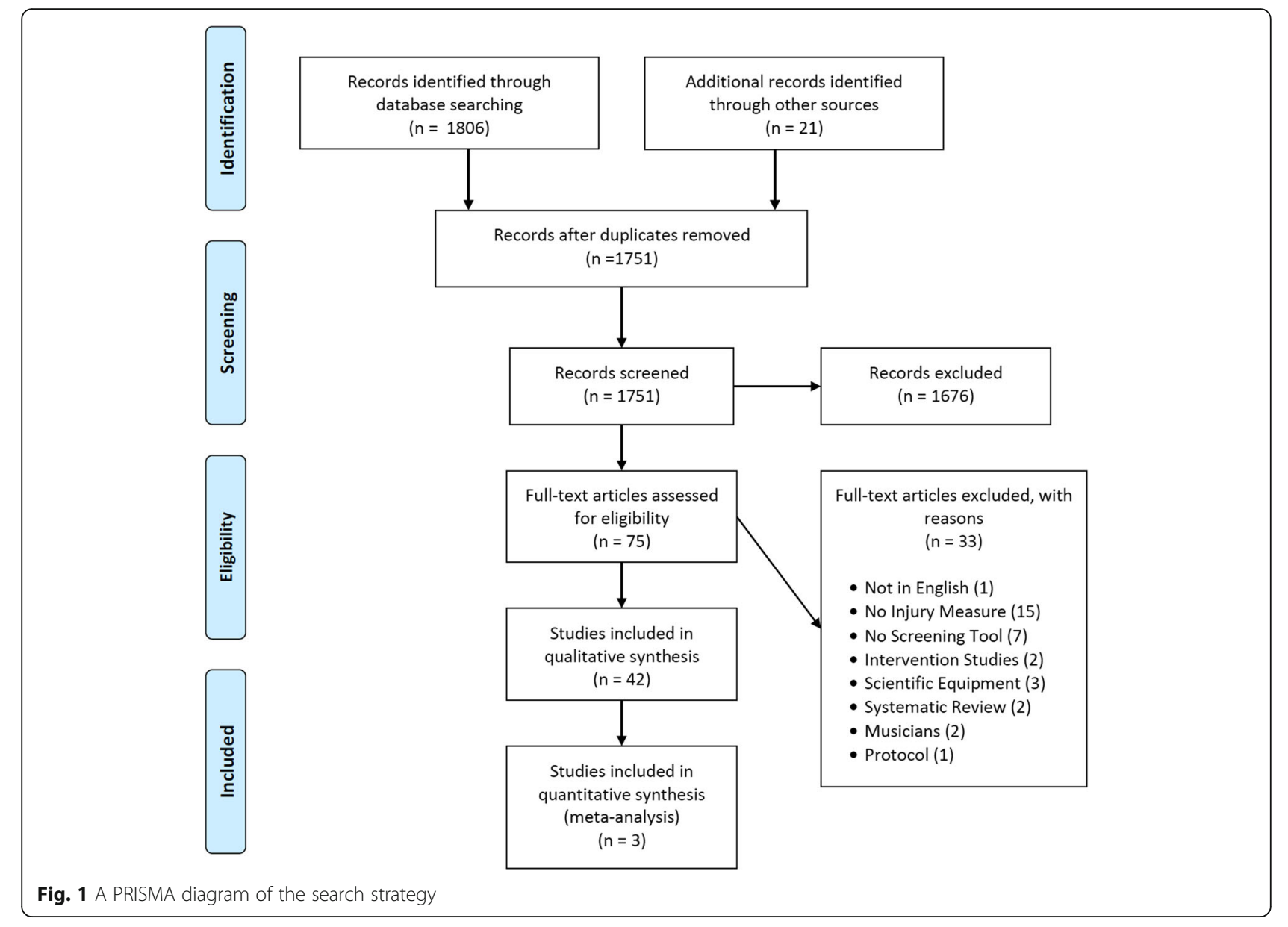

group of dancers $[41,46,47]$, and in two studies, the level was unclear $[40,43]$.

Fourteen studies considering dancers under 18 years old $[26,34-36,38,39,43,49,53,55,59,61,63,64]$ and 16 studies including dancers above 18 years old [24, 27, $29,40,44-48,50,52,54,58,60,62,65]$. Eight studies included dancers across this age range [5, 28, 30-32, 41, $56,57]$, and four studies did not report the age [33, 37, $42,51]$. Gender reporting revealed that 13 studies included females only [26, 31, 32, 34, 39, 40, 43, 44, 49, 52, $60,63,64]$, 28 studies were mixed [5, 24, 27-30, 35-38, $41,42,45-48,50,51,53-59,61,62,65]$ and in one study, the gender was unclear [33].

Twenty-five studies provided a definition of injury [24, $27,28,30-32,38,39,44-48,50-59,62,63]$, and 17 studies did not define the injury $[5,26,29,33-37,40-$ $43,49,60,61,64,65]$. In eight studies diagnosis was provided by a physical therapist/physiotherapist or doctor [26-28, 38, 44, 49, 55, 64]. In 29 studies [5, 24, 29-32, $34-36,39,41-43,45-48,50-54,56-59,61,62,65]$, injury was self-reported, and in three studies [33, 37, 63], the method of diagnosis was unclear. In one study, the diagnosis was provided by a 'healthcare professional'
[60], and in one study, a nurse practitioner provided the diagnosis [40]. Five studies investigated a specific type of injury: lumbosacral pain [35], stress fractures [40], lateral ankle sprain [53], low back pain [59] and patellofemoral pain syndrome (PFPS) [63].

Fourteen studies used regression models or risk measurement $[27,31,38,44,46,47,50,52,53,56,57,60,61$, $65]$, and 18 studies used inferential analysis that did not include regression or risk measurements $[5,24,26,29$, 30, 32, 34-36, 39, 40, 42, 43, 45, 48, 54, 58, 59]. Seven studies used both types of statistical analysis [28, 41, 49, $55,62-64]$, and in three studies, the method of analysis was unclear [33, 37, 51].

\section{Range of Motion}

Twenty-eight studies $[5,24,26,28-30,32,33,35,38$, $39,43,44,46-49,51-56,58-60,63,65]$ investigated the relationship between ROM and injury. With regard to genre, 11 studies included ballet dancers [24, 26, 28-30, $32,33,35,38,39,43]$, one study included contemporary dancers [44], three studies included Irish dancers [46$48]$ and seven studies included a mixed group [49, 5156]. In five studies, genre was unclear [5, 58-60, 63], 


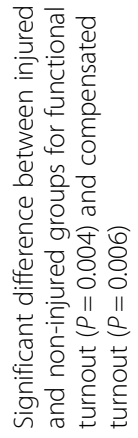

प⿺

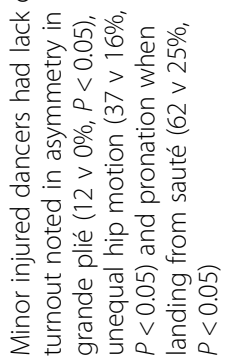

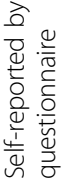

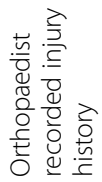

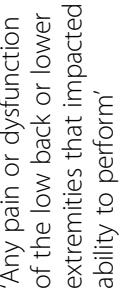

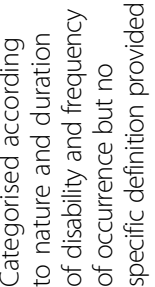

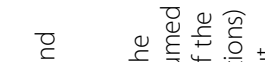

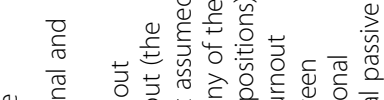

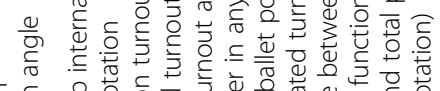

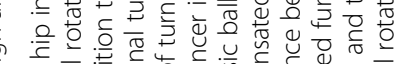

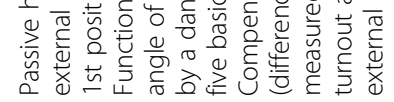

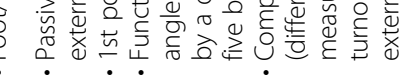

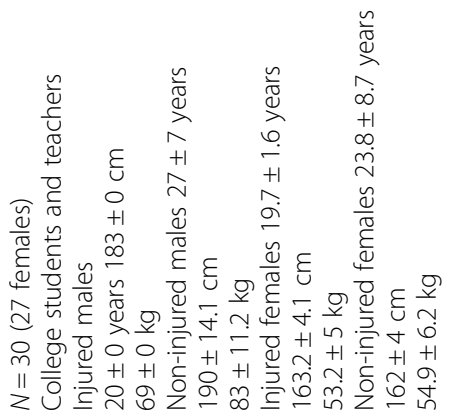

$\underset{\substack{\stackrel{T}{d} \\ \frac{0}{0} \\ \frac{0}{0}}}{0}$

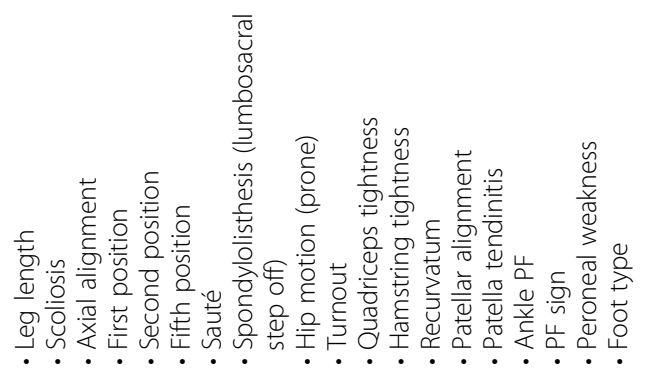

4

o

$\stackrel{4}{\rightleftharpoons}$

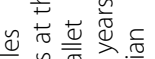

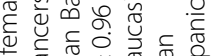

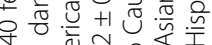

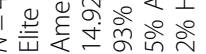

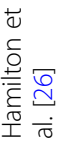



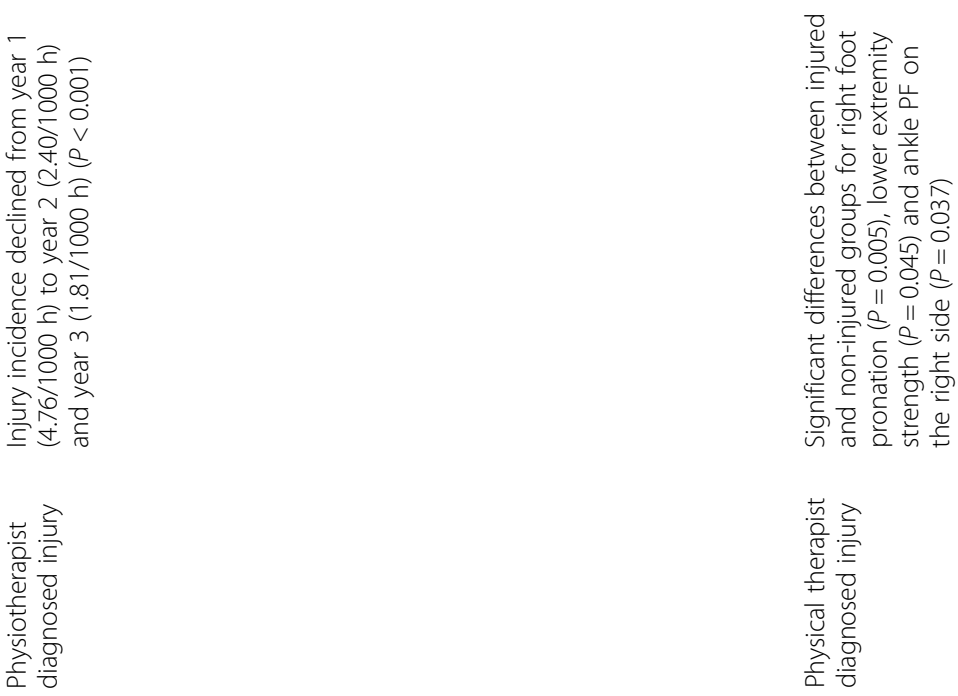

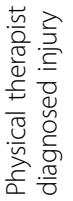

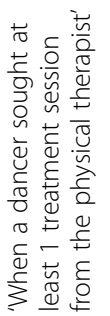

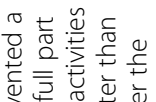

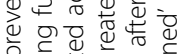

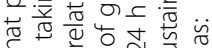

¿

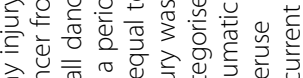

专贾. .

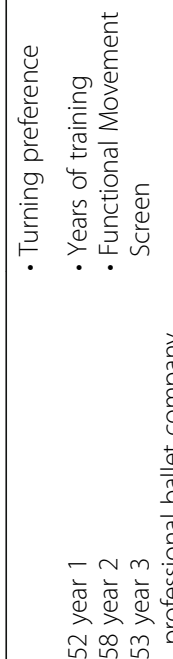

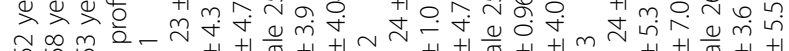

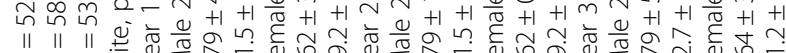

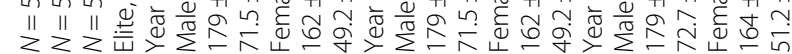

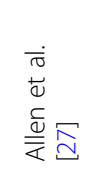

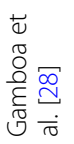

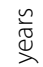

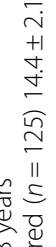

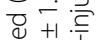

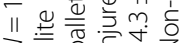

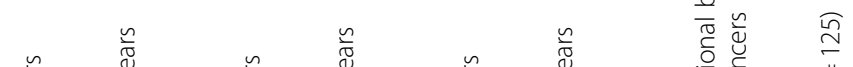

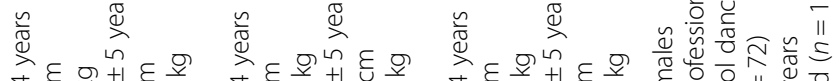

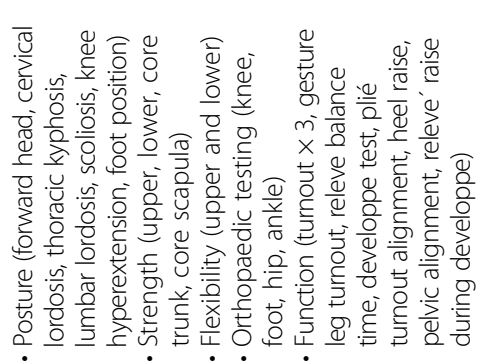

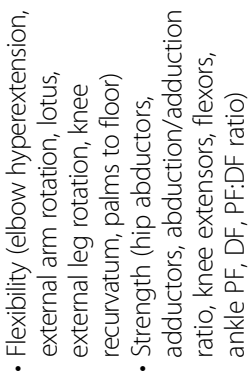

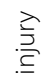
4

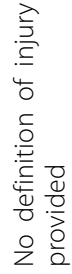

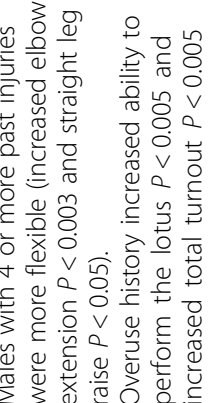

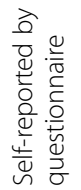

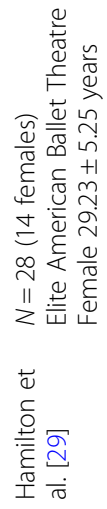




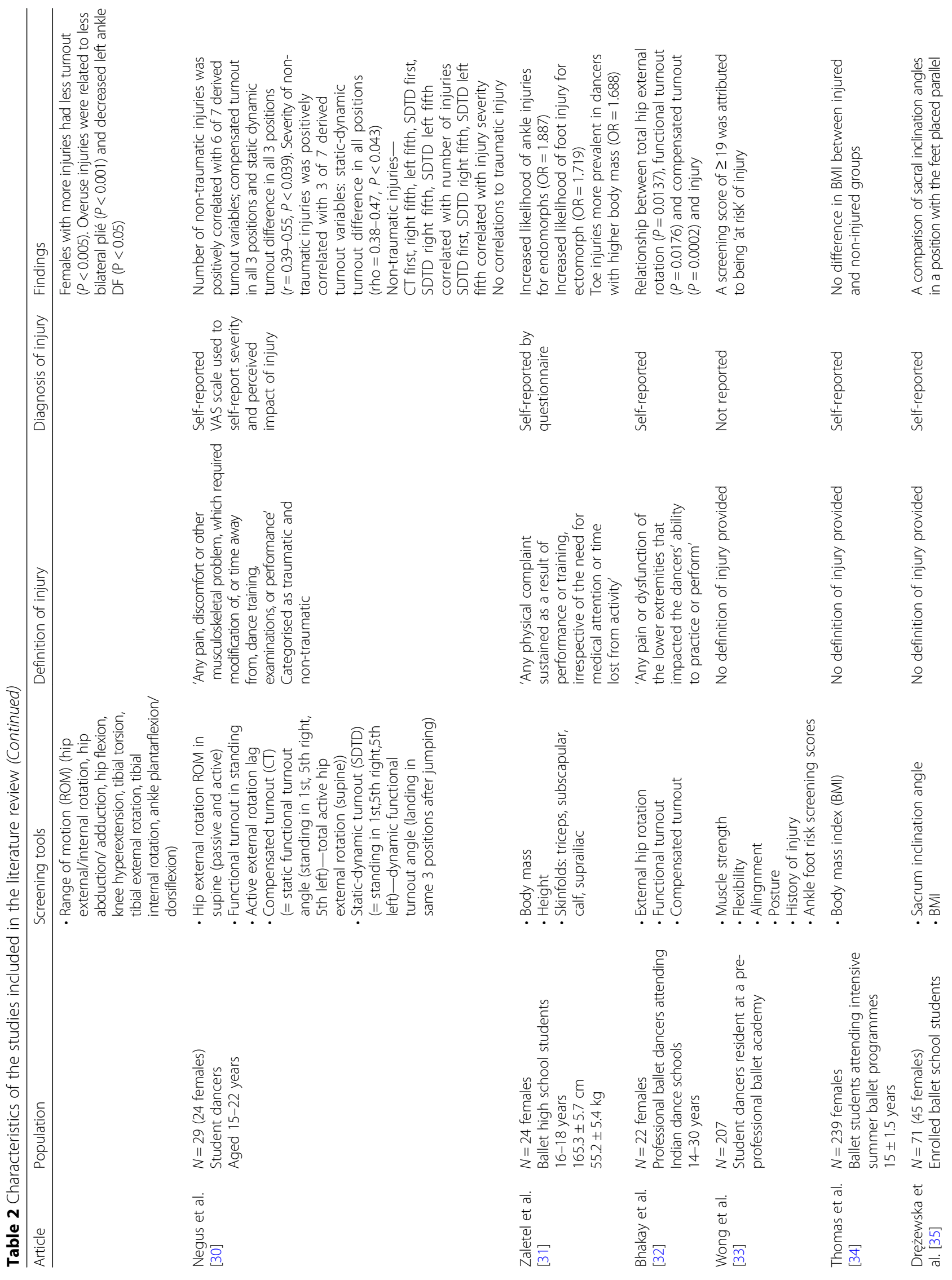




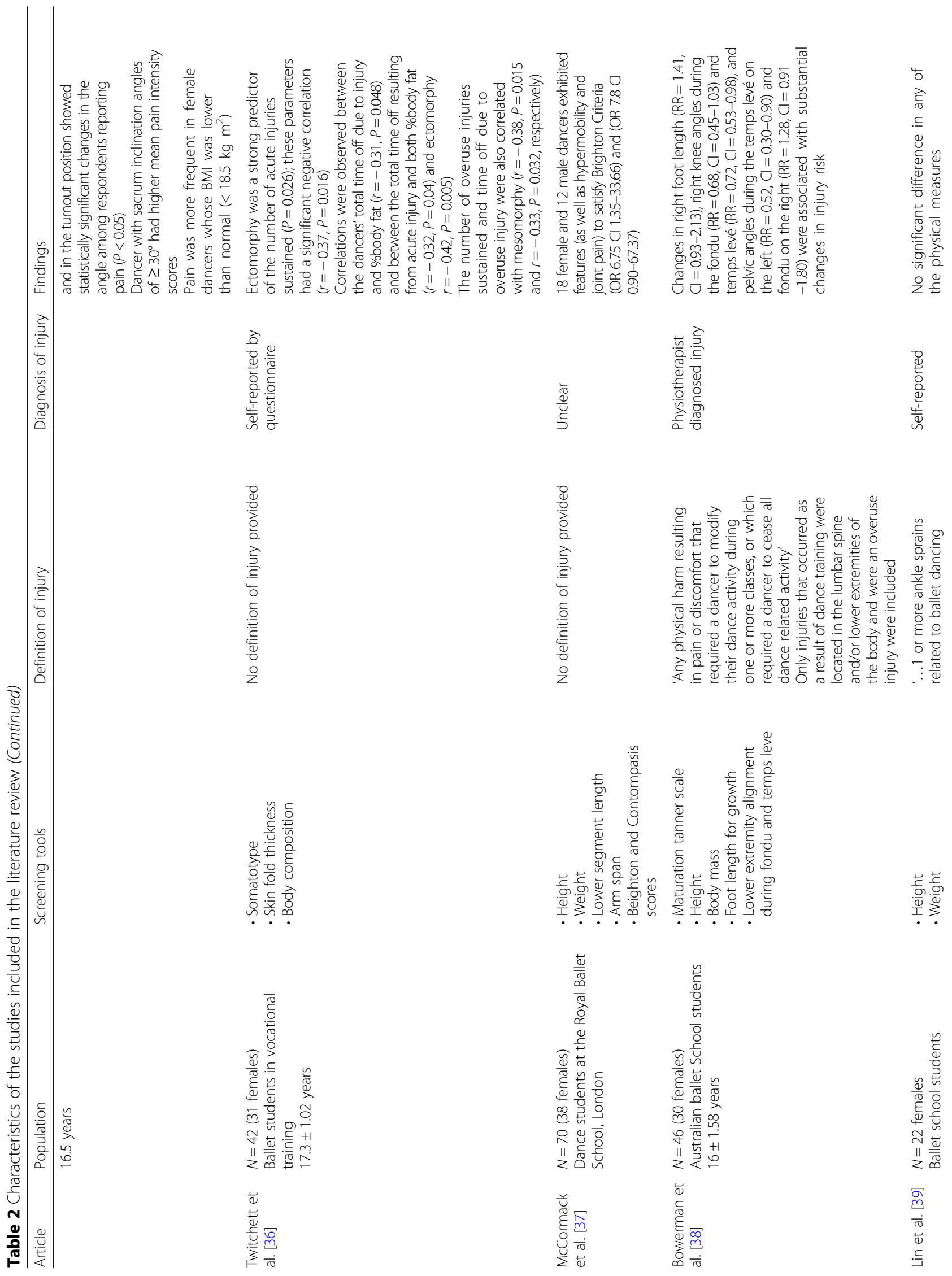




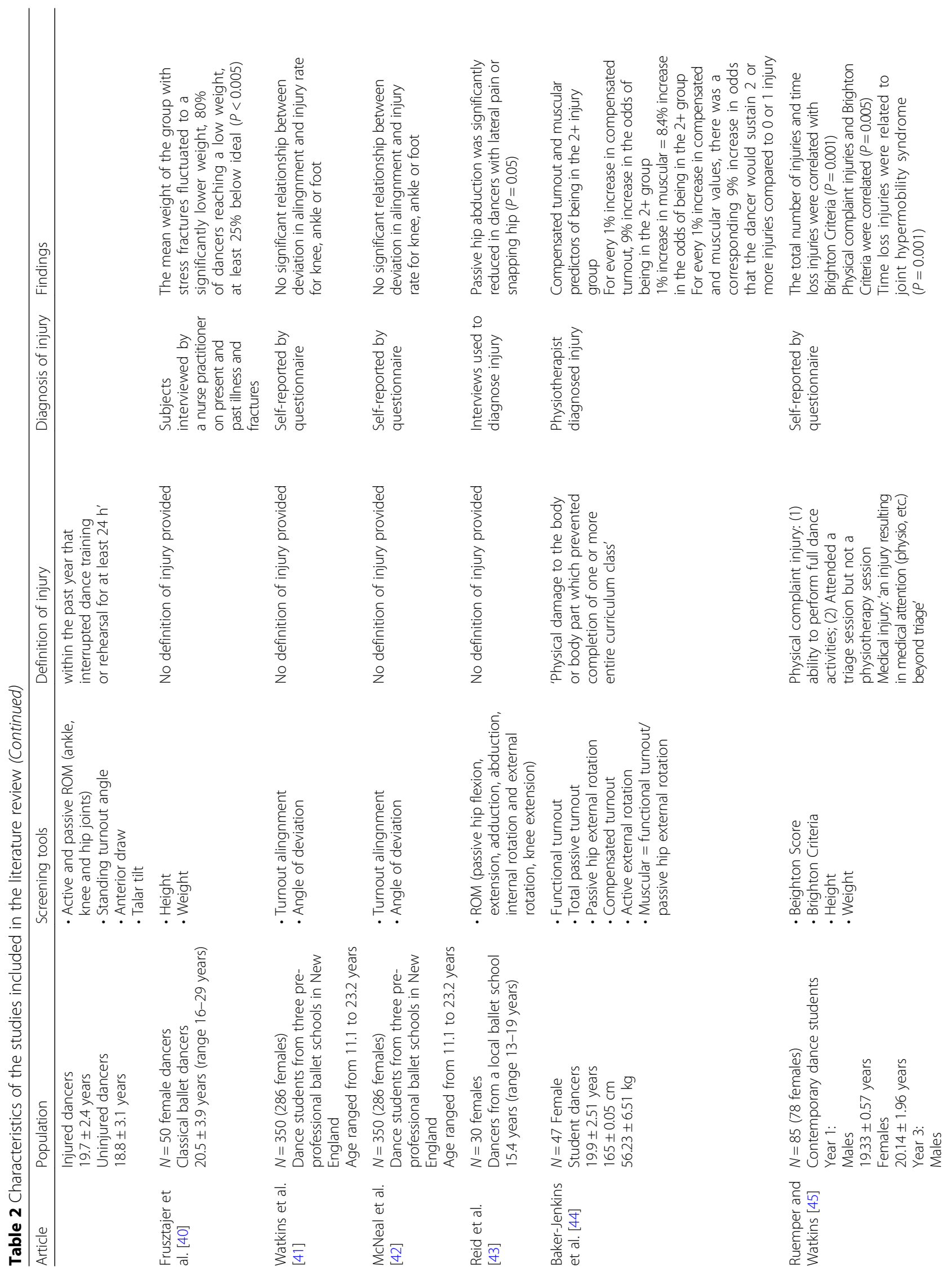




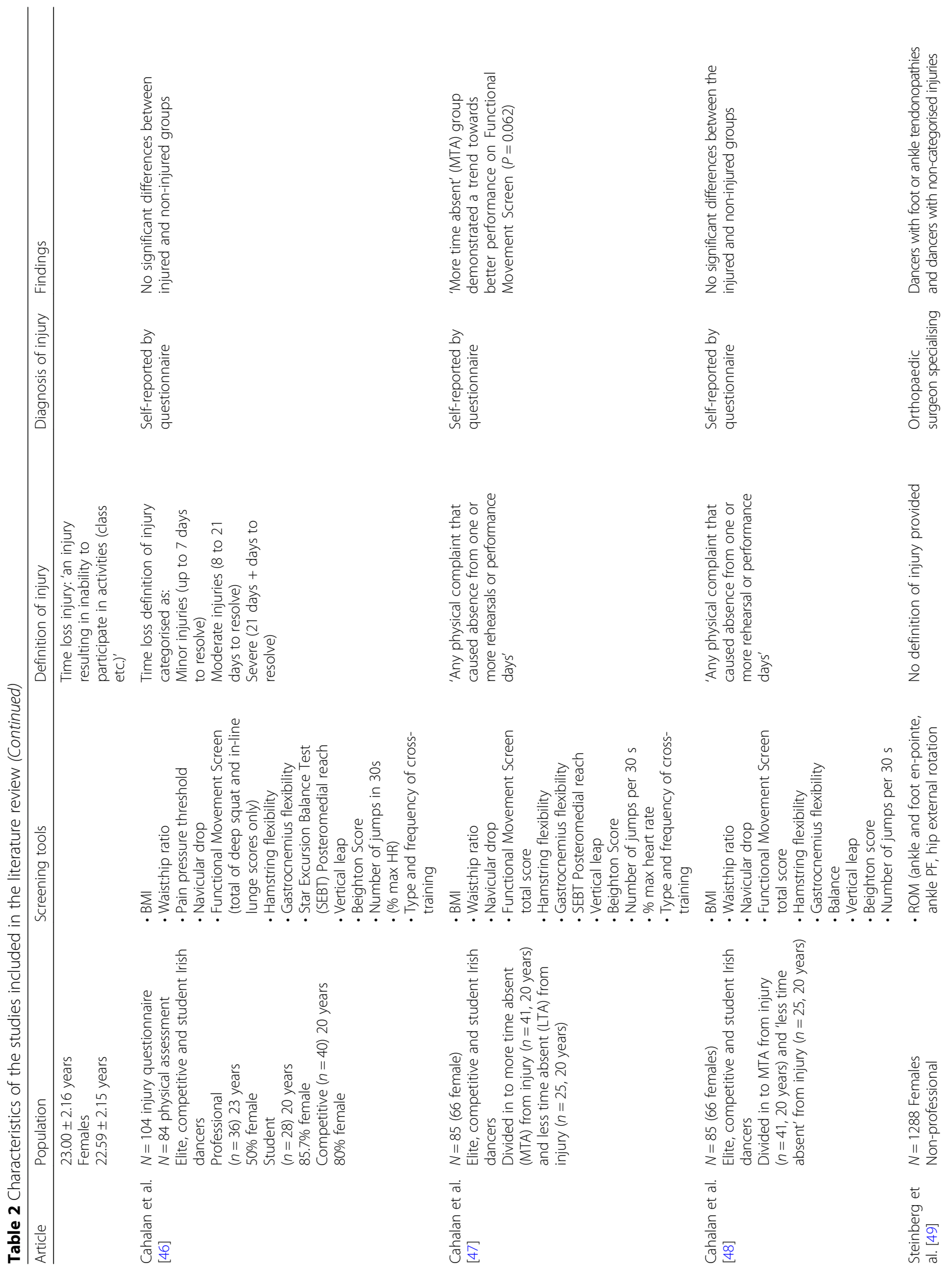




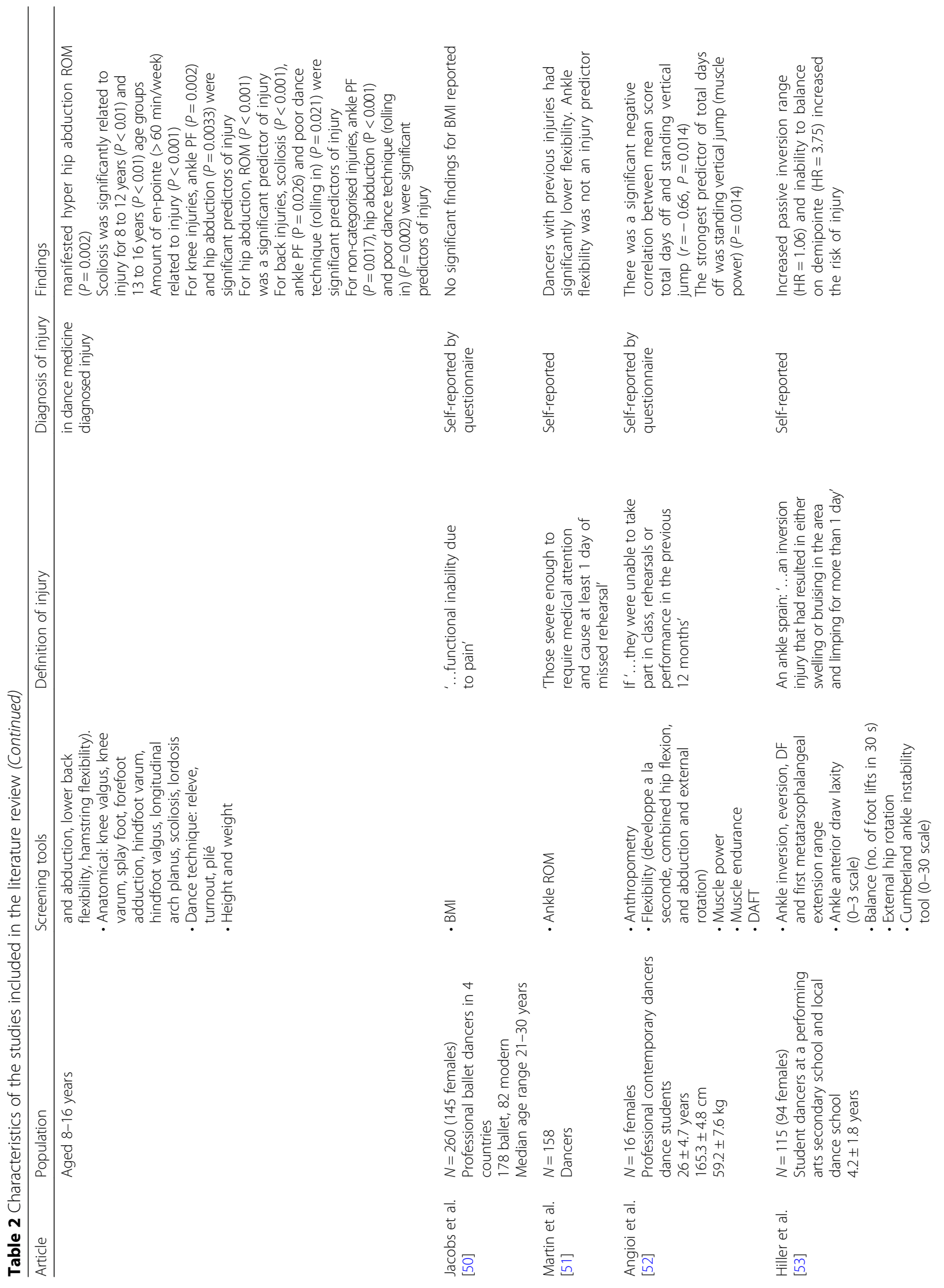




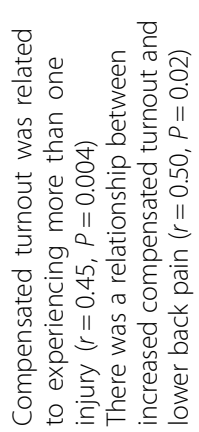

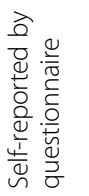

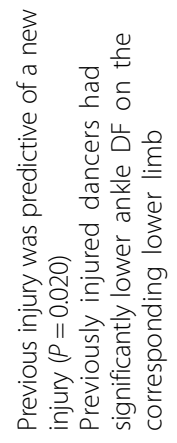

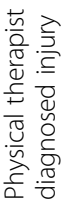

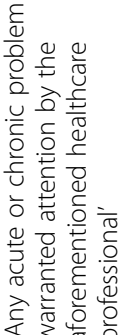

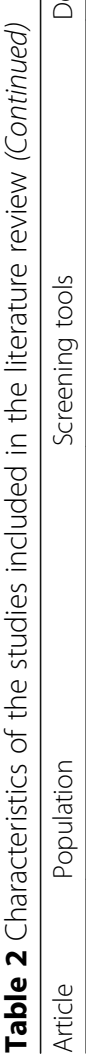

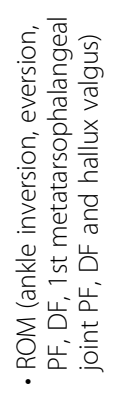

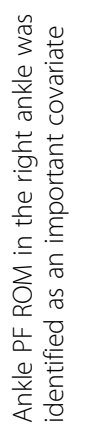

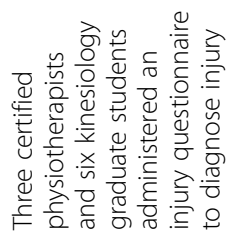

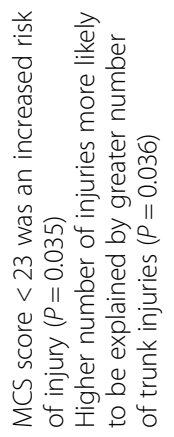

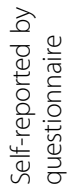

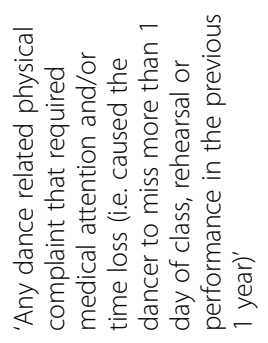

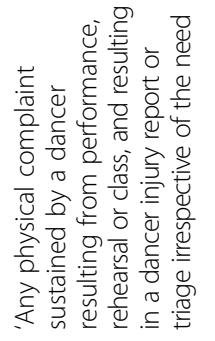

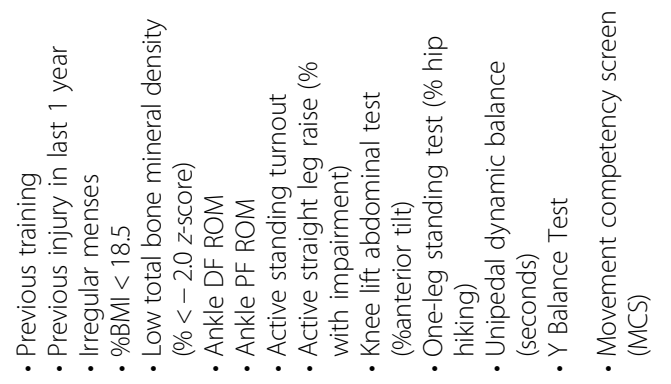

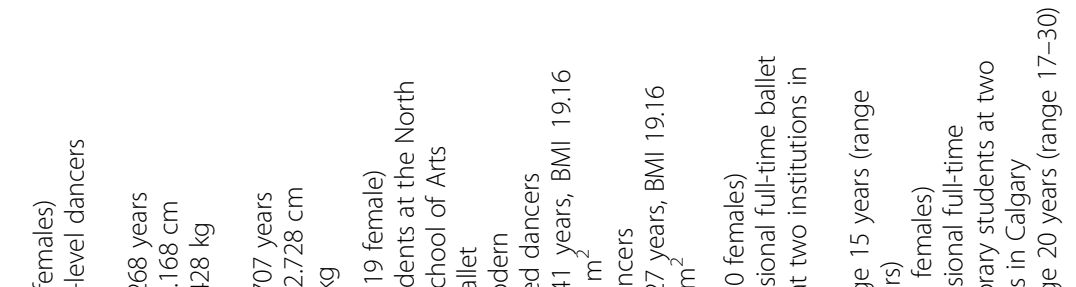

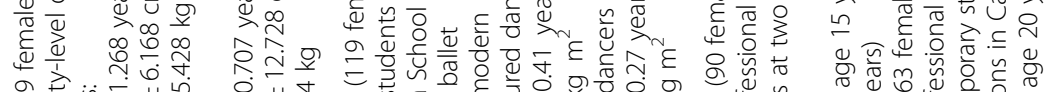

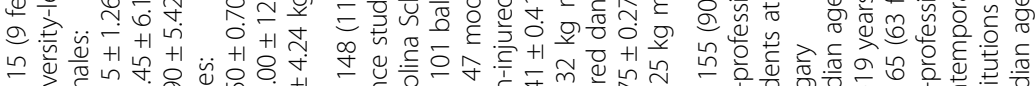

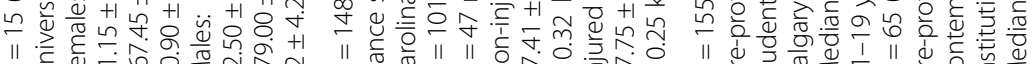



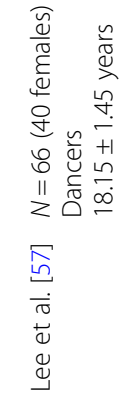




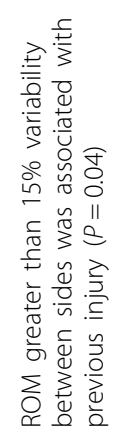

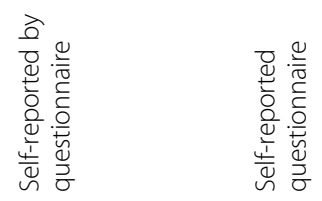

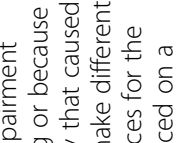

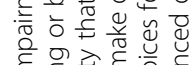

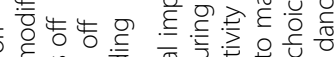

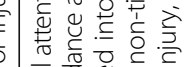
言 흠

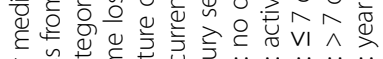

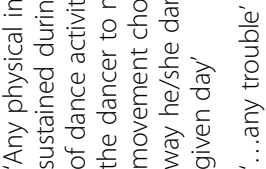

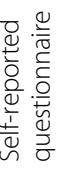

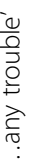
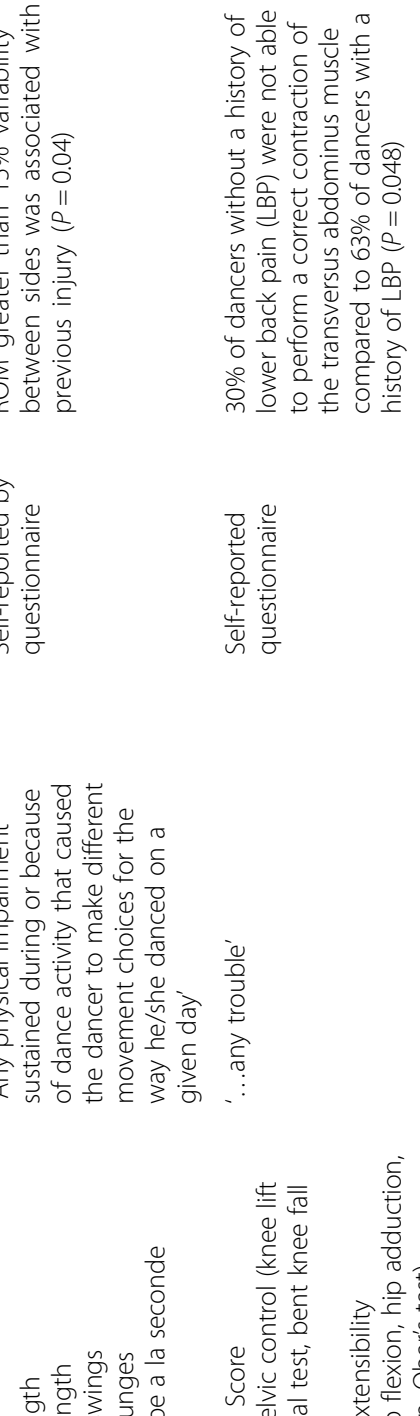

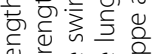

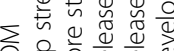

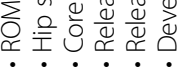
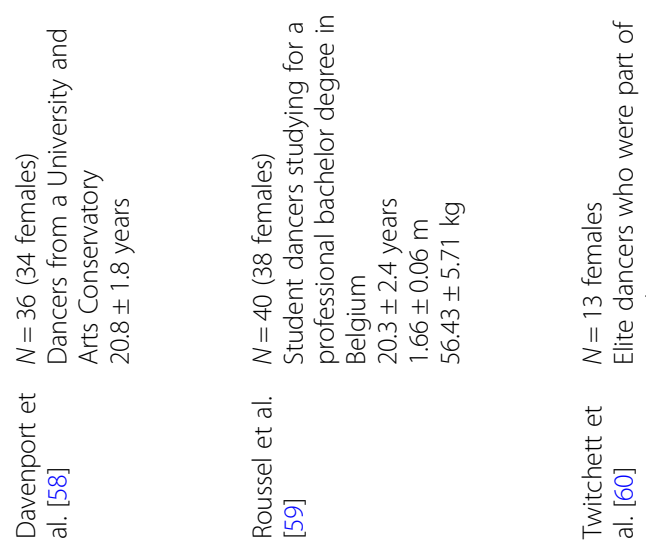
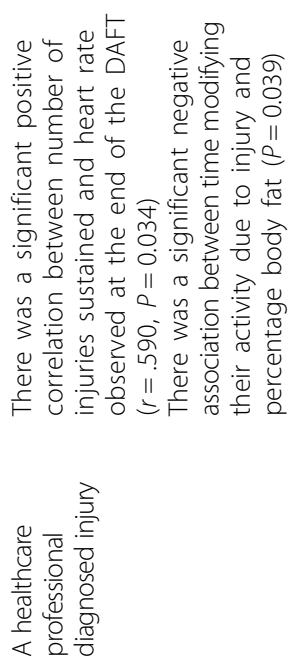

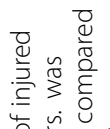

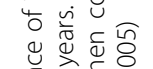

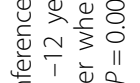

㐫亡 㐫

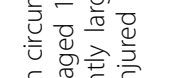

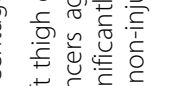

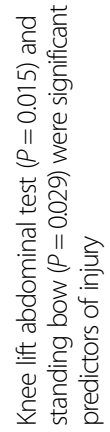

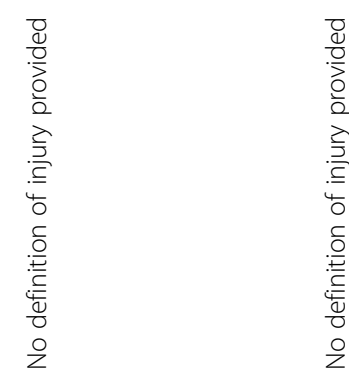

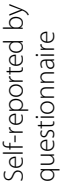
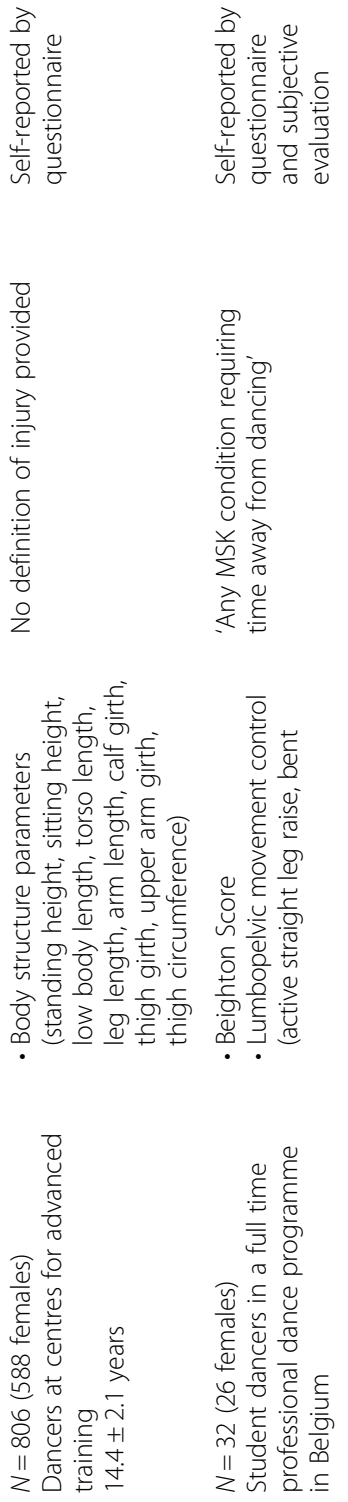

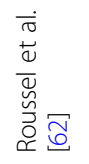



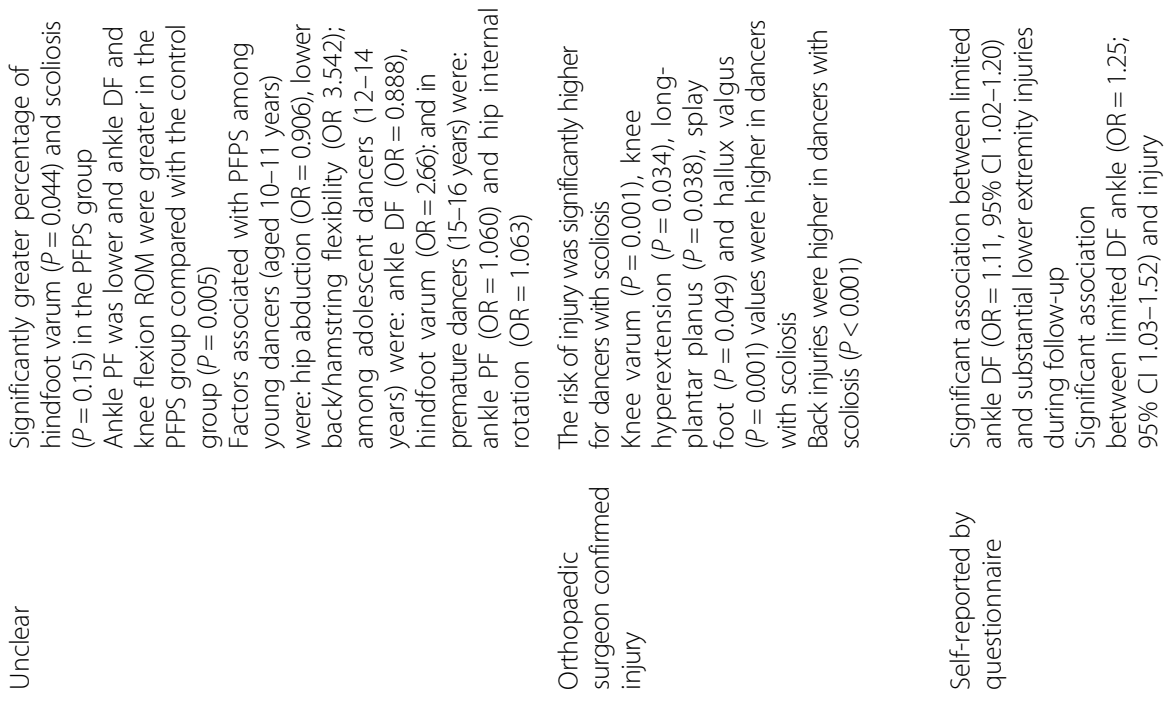

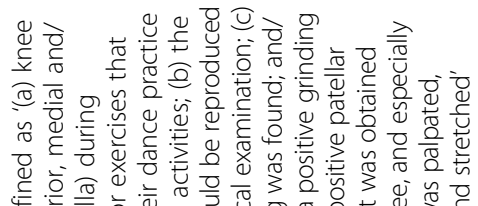

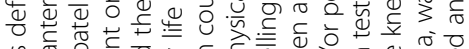

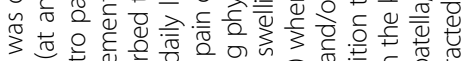

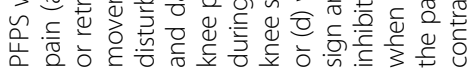

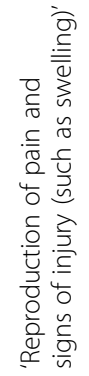

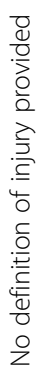
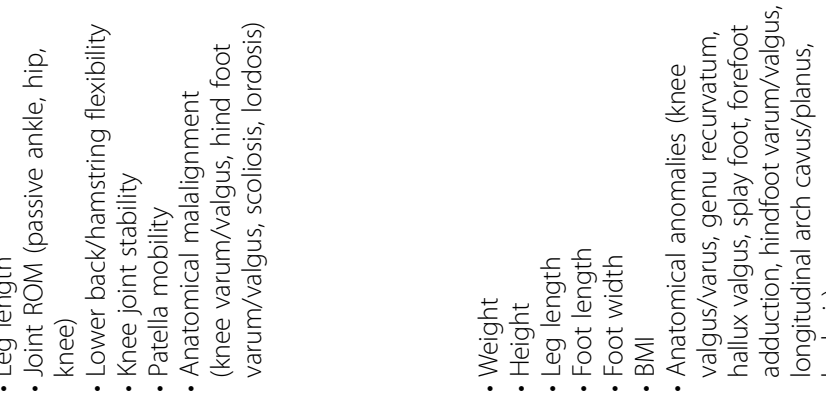

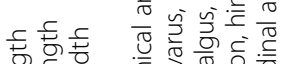

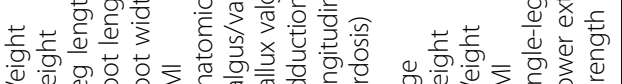

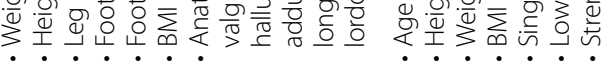
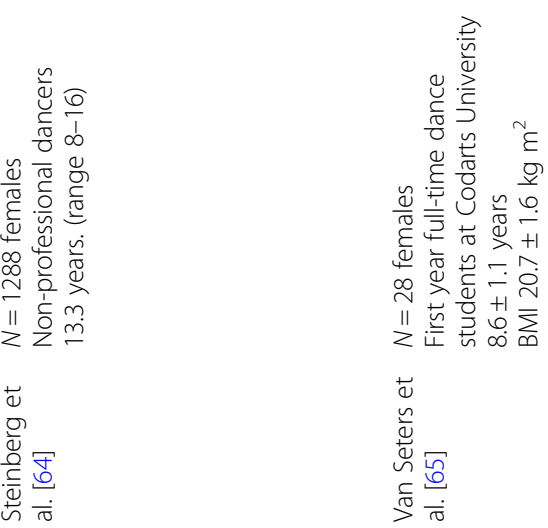

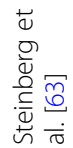

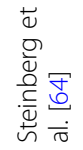

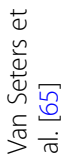


and one study used dance degree students but did not state the genre [65]. Five studies contained dancers classified as elite/professional [26, 28, 29, 48, 60] and five studies as pre-professional [5, 33, 56, 58, 59]. Sixteen studies used non-elite/non-professional dancers [24, 30, $32,35,38,39,43,44,49,51-55,63,65]$, and two studies used a mixed group of dancers [46, 47]. Nine studies used dancers under 18 years old [26, 35, 38, 39, 43, 49, $53,59,63]$, and 11 studies used dancers above 18 years old $[24,29,44,46-48,52,54,58,60,65]$. Six studies included dancers spanning the age ranges 9-20 years, [28], $14-18$ years [5], 15-22 years [30], 14-30 years [32], 1228 years [55] and $17-30$ years [56]. Two studies did not report the age $[33,51]$. Nine studies included females only $[26,32,39,43,44,49,52,60,63], 18$ studies were mixed $[5,24,28-30,35,38,46-48,51,53-56,58,59$, 65 ] and one study was unclear [33].

Nineteen studies provided a definition of injury [24, $28,30,32,38,39,44,46-48,51-56,58,59,63]$, and nine studies did not define the injury $[5,26,29,33,35,43,49$, $60,65]$. Injury diagnosis was provided by a physical therapist/physiotherapist or doctor in six studies $[26,28,38$, $44,49,55]$ and was self-reported in 19 studies [5, 24, 29, $30,32,35,39,43,46-48,51-54,56,58,59,65]$. In two studies [33, 63], it was unclear who made the diagnosis, and in one study, a 'healthcare professional' made the diagnosis [60].

Nine studies used regression models or risk measurements [38, 44, 46, 47, 52, 53, 56, 60, 65], and 13 studies used inferential analysis that did not include regression or risk measurements $[5,24,26,29,30,32,35,39,43$, $48,54,58,59]$ to determine which factors have an association with injury. Four studies used both types of statistical analysis $[28,49,55,63]$, and analysis was unclear in two studies $[33,51]$.

\section{Hip and Spine}

'Minor injured' dancers had unequal hip motion (37 v $16 \% ; P<0.05)$ [26], and hip hyperabduction was related to foot or ankle tendinopathies and non-categorised injuries $(P=0.002)$ [49]. In dancers aged $10-11$ years, hip abduction (OR 0.906; $P=0.021 ; 95 \%$ confidence intervals
(CI) 0.833-0.985) was associated with PFPS. In dancers aged 15-16 years, hip internal rotation (OR 1.0603; $P=0.003 ; 95 \%$ CI $1.021-1.107)$ was associated with PFPS. In 10-11 year old dancers, lower back and hamstring flexibility (OR 3.542; $P=0.046)$ were a predictor of PFPS [63]. Total hip external rotation was related to injury in non-professional ballet dancers $(P=0.0137)$ [32]. Asymmetric hip internal rotation was associated with prior but not current injury with dancers demonstrating a $10^{\circ}$ difference between the right and left limb $(P=0.04)$ [58]. At the sacrum, ballet students with an inclination angle of $\geq 30^{\circ}$ had significantly greater $(P<0.05)$ mean low back pain intensity scores [35].

Meta-analysis Following a review of the included studies, only passive hip external rotation was eligible for meta-analysis $[24,39]$. The pooled mean difference was $-2.44^{\circ}$ (95\% CI $\left.-5.76-0.88 ; P=0.15 ; I^{2}=0 \%\right)$ indicating that there was no difference in this screening measurement between injured and non-injured groups (Fig. 2).

\section{Knee}

A study of elite female dance students reported that 'drop outs', some of whom suffered an injury, had a minus recurvatum $(25 \mathrm{v} 0 \% ; P<0.01)$ and straight legs (75 v 45\%; $P<0.05$ ) [26]. In pre-professional dancers, left popliteal angle was found to be correlated with injury $(r$ $=0.340 ; P=0.03)$ [5]. In 12-14-year-old dancers with PFPS, greater patella mobility was reported (OR 2.666; $P=0.029)[63]$.

\section{Ankle}

Significant differences between injured and non-injured dancers have been reported for right foot pronation with injured pre-professional ballet dancers $74 \%$ more likely to have a pronated right foot (RR 1.74; 95\% CI 1.192.54; $P=0.005)$ and insufficient right ankle plantarflexion (RR 1.50; 95\% CI 1.05-2.15; $P=0.037$ ) [28]. In dance degree students, multivariate analysis of ROM during a single-leg squat identified that limited ankle dorsiflexion (OR 1.25; 95\% CI 1.03-1.52) was a risk factor for substantial lower extremity injury as did univariate analysis

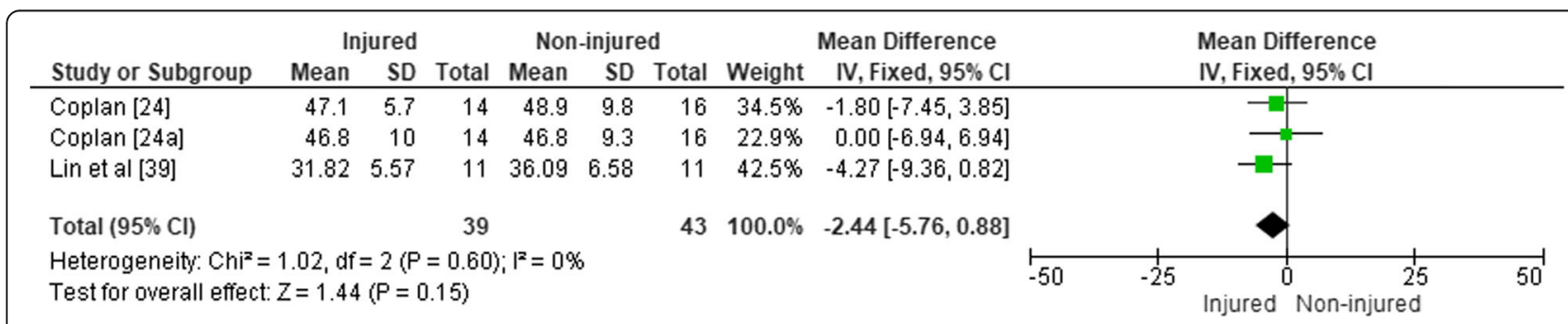

Fig. 2 Forest plot of the comparison of hip external rotation between injured and non-injured dancers. Note: Coplan is reported twice as the author measured both right [24] and left [24a] limbs 
(OR 1.11; 95\% CI 1.02-1.20) [65]. Increased passive inversion range was related to ankle sprain in adolescent dancers $(\mathrm{HR}=1.06 ; 95 \%$ CI 1.00-1.12) [53]. A greater percentage of hindfoot varus (OR 2.66; $P=0.004)$ and ankle dorsiflexion (OR 0.888; $P=0.026$ ) existed in injured female adolescent dancers aged 12-14 years, and limited ankle plantarflexion (OR 1.060; CI 1.015-1.107; $P=0.009)$ was a predictor of PFPS in female adolescent dancers aged 15-16 years [63]. Overuse injuries occurred in female ballet dancers with decreased left ankle dorsiflexion $(P<0.005)$ [29].

\section{Upper Limb}

Male ballet dancers with four or more past injuries were reported to have increase elbow extension $(P<0.003)$ in comparison with other male ballet dancers [29]; however, no specific information was provided regarding injury location or limb dominance.

\section{Anthropometric and Posture}

Twenty-seven studies investigated the relationship between anthropometric values and/or posture and injury $[5,26,28,29,31,33-40,43,45-50,52,56,60,61,63-$ 65]. Thirteen studies included ballet dancers [26, 28, 29, $31,33-40,43]$, one study included contemporary dancers [45], four studies include a mixed group of dancers $[49,50,52,56]$, three studies involved Irish dancers [46-48], five studies were unclear $[5,60,61,63$, $64]$ and one study used dance degree students without further detail on the genre [65]. Seven studies contained dancers classified as elite/professional [26, 28, 29, 37, 48, $50,60]$, three studies as pre-professional $[5,33,56]$ and 14 studies as non-elite/non-professional [31, 34-36, 38, $39,43,45,49,52,61,63-65]$. Two studies used a mixed group of levels $[46,47]$, and in one study, the level was unclear [40].

Eleven studies used dancers under 18 years old [26, 34-36, 38, 39, 43, 49, 61, 63, 64], ten studies above 18 years old [29, 40, 45-48, 50, 52, 60, 65] and four studies included dancers that spanned the age ranges 920 years [28], 14-18 years [5], 16-18 years [31] and 1730 years [56] and in two studies the age was not stated $[33,37]$. Eleven studies included females only [26, 31, $34,39,40,43,49,52,60,63,64], 15$ studies were mixed $[5,28,29,35-38,45-48,50,56,61,65]$ and one study was unclear [33].

Twelve studies defined the injury $[28,31,38,39,45-48$, $50,52,56,63]$, but 15 studies did not define the injury [ 5 , $26,27,33-37,40,43,49,60,61,64,65]$. Injury diagnosis was provided by a physical therapist/physiotherapist or doctor in five studies $[26,28,38,49,64]$ and was self-reported in 17 studies [5, 29, 31, 34-36, 39, 43, 45-48, $50,52,56,61,65]$. In three studies, it was unclear [33, 37, 63] who made the diagnosis. In one study, a 'healthcare professional' made the diagnosis [60], and in one study, a nurse practitioner provided the diagnosis [40].

Ten studies used regression models or risk measurements [31, 38, 46, 47, 50, 52, 56, 60, 61, 65], and 11 studies used inferential analysis that did not include regression or risk measurements $[5,26,29,34-36,39,40$, $43,45,48]$ to determine which factors have an association with injury. Statistical analysis was unclear in two studies [33, 37]. Four studies used both types of statistical analysis [28, 49, 63, 64].

A higher incidence of spondylolisthesis was reported in ballet students who dropped out the profession in comparison with those who continued $(60 \mathrm{v} 11 \% ; P<0.05)$ [26]. In non-professional dancers, scoliosis was related to injury for 8 to 12 -year-olds $\left(X^{2}=12.379 ; \mathrm{df}=1 ; P<0.01\right)$, and for 13 to 16 -year-olds $\left(X^{2}=30.8\right.$; $\left.\mathrm{df}=1 ; P<0.01\right)$, injury risk among scoliotic dancers (8-12 years) was 1.62 greater than non-scoliotic dancers and 1.52 greater than 13 to 16 -year-old non-scoliotic dancers $(P<0.001)$ [49]. In the scoliotic group, the most common injuries were to the back (47\%) and knee (27\%), whilst in the non-scoliotic group, it was the knee (47\%) and non-categorised injuries (25.5\%) $\quad(P<0.001) \quad[49]$. In non-professional female dancers aged $8-16$ years, there was a higher prevalence of back injuries in scoliotic dancers $(\mathrm{OR}=19.4 ; 95 \%$ CI $10.2-$ $36.4 ; P<0.001$ ), and significantly, more injured dancers were found among the scoliotic group (59.6\%) than non-scoliotic group $(37.5 \%)(P=0.012)$. The RR for scoliotic dancers was higher than the non-scoliotic group for all age cohorts and significantly at the age of 9 years and from 13 to 15 years old [64]. In 15-16-year-old dancers, scoliosis was a significant predictor of PFPS (OR 5.209, 95\% CI 1.353-20.052; $P=0.016$ ) [63].

In a study of 806 young dancers, left thigh circumference of dancers aged 11 to 12 years was significantly larger compared to non-injured dancers $(P<0.05)$ [61]. With reference to body type, an increased likelihood of ankle injury for endomorphs was reported (OR $=1.887$; 95\% CI 1.4332.312; $P=0.03$ ) and increased likelihood for foot injury for ectomorphs $(\mathrm{OR}=1.719 ; 95 \%$ CI 1.081-2.899; $P=0.05)$ with toe injuries more prevalent in higher body mass $(\mathrm{OR}=1.688 ; 95 \%$ CI 1.410-3.121; $P=0.03)$ [31]. Twitchett et al. [60] reported a significant negative association between 'time modifying their activity due to injury' in elite female dancers and percentage body fat $(r=-.614$; $P=0.026)$ and $(P=0.039)$ using Spearman correlation coefficient and backward regression analysis respectively. Twitchett et al. [36] reported that in ballet students, ectomorphy was a strong predictor of the number of acute injuries sustained $(P=0.026)$, and these parameters had a significant negative correlation $(r=-0.37 ; P=0.016)$. Significant negative correlations were observed between the dancers 'total time off due to injury' and percentage body fat $(r=-0.31 ; P=0.048)$ 
and between the 'total time off' resulting from acute injury and percentage body fat $(r=-0.32 ; P P=0.04)$ and ectomorphy ( $r=-0.42, P=0.005)$. The number of overuse injuries and 'time off' due to overuse injury was correlated with mesomorphy $(r=-0.38 ; P=0.015$ and $r=-0.33 ; P=0.032$ ). The mean group weight of $80 \%$ of ballet dancers with stress fractures was found to be $25 \%$ below the ideal weight $(P<0.005)$ [40]. Low back pain was more frequent in women whose body mass index was $<18.5$ than those $>18.5(P<0.05)$ [35].

In elite adolescent ballet dancers, changes in right foot length were reported to be associated with changes in injury risk with a change of $0.5 \mathrm{~cm}$ associated with a moderately increased risk of injury (RR 1.41; OR 0.932.13) [38].

\section{Dance-Specific Positions}

Fifteen studies investigated the relationship between dance-specific positions and injury $[24,26,28,30,32$, $38,39,41,44,49,52-54,56,58]$. Eight studies included ballet dancers [24, 26, 28, 30,32, 38, 39, 41], one study included contemporary dancers [44], five studies were mixed $[49,52-54,56]$ and one study genre was unclear [58]. Two studies contained dancers classified as elite/ professional $[26,28]$, and ten studies as non-elite/non-professional [24, 30, 32, 38, 39, 44, 49, 52-54]. Two studies classified dancers as pre-professional $[56,58]$, and one study contained mixed levels of dancers [41]. Five studies used dancers under 18 years old [26, 38, 39, $49,53]$, five studies above 18 years old [24, 44, 52, 54, 58] and five studies included dancers spanning the age ranges 9-20 years [28], 15-22 years [30], 14-30 years [32], 11.125.1 years [41] and 17-30 years [56]. Six studies included females only [26, 32, 39, 44, 49, 52], and nine studies were mixed [24, 28, 30, 38, 41, 53, 54, 56, 58].

Twelve studies defined the injury [24, 28, 30, 32, 38, $39,44,52-54,56,58]$, and three studies did not define the injury $[26,41,49]$. Injury diagnosis was provided by a physical therapist/physiotherapist or doctor in five studies $[26,28,38,44,49]$ and was self-reported in ten studies [24, 30, 32, 39, 41, 52-54, 56, 58].

Six studies used regression models or risk measurement [38, 41, 44, 52, 53, 56], and eight studies used inferential analysis that did not include regression or risk measurements $[24,26,30,32,39,49,54,58]$ to determine which factors were associated with injury. Statistical analysis involved both types of analysis in one study [28].

In elite female dance students, a lack of turnout resulting in an asymmetry in the grand plié $(12 \mathrm{v} 0 \% ; P<0.005)$ and pronation when landing from sauté $(62 \mathrm{v} 25 \%$; $P<0.05)$ existed in 'minor injured' dancers [26]. First year 'drop outs' had a weak sauté $(12 \mathrm{v} 0 \%$; $>0.05)$, and third and fourth year 'drop outs', a poor relevé ( 60 v 11\%;
$P<0.01)$ and impaired turnout of hips (pronation in plié) (40 v 0\%; $P<0.05$ ) [26].

A significant difference existed between injured and non-injured ballet dancers for functional turnout $(P=0.004)$ and compensated turnout $(P=0.006)$ with mean compensated turnout $25.4^{\circ}$ in injured and $4.7^{\circ}$ in non-injured [24]. A $1 \%$ increase in compensated turnout resulted in a $9 \%$ increase in the odds of been in the 2+ injuries group compared to the no injury or 1 injury group. Compensated turnout difference ratio was a significant predictor of been in the 2+ injuries group (OR 1.090; 95\% CI $1.002-$ 1.186; $P=0.046)$ as was muscular value ratio calculated by functional turnout/passive external hip rotation (OR 1.084; 95\% CI 1.021-1.15; $P=0.008$ ) [44]. Negus et al. [30] reported that the number of non-traumatic injuries was positively correlated with six of seven derived turnout variables, compensated turnout in all three positions and static dynamic turnout difference in all three positions $(r=0.39-0.55 ; P<0.039)$. These variables were compensated turnout first position $(r=0.39 ; P=0.035)$, compensated turnout right fifth position $(r=0.41 ; P=0.028)$, compensated turnout left fifth position $(r=0.42 ; P=0.023)$, static dynamic turnout difference first position $(r=0.39$; $P$ $=0.039$ ), static dynamic turnout difference right fifth position $(r=0.51 ; P=0.005)$ and static dynamic turnout difference left fifth position $(r=0.55 ; P=0.002)$. Severity of non-traumatic injuries positively correlated with three of seven derived turnout variables: static-dynamic turnout difference in all positions, static dynamic turnout difference first position $(r=0.38 ; P=0.043)$, static dynamic turnout difference right fifth position $(r=0.44 ; P=0.017)$ and static dynamic turnout difference left fifth position $(r=0.47 ; P=0.010)$.

Functional turnout $(P=0.0176)$ and compensated turnout $(P=0.0002)$ were related to injury in non-professional ballet dancers [32]. In university-level dancers, compensated turnout was found to be significantly related to experiencing more than one injury (traumatic and overuse combined) $(r=0.45 ; P=0.04)$. Further analysis suggested that compensated turnout may result in more than one traumatic injury $(r=0.45 ; P=0.04)$ whilst no significant relationship existed between compensated turnout and overuse injuries $(r=0.20 ; P=0.36)$. Furthermore, a significant relationship existed between increased compensated turnout and low back pain $(r=0.50 ; P=0.02)$ [54]. In adolescent ballet dancers, a $10^{\circ}$ greater right knee alignment resulted in a moderate decrease in injury risk in the fondu $(\mathrm{RR}=0.68 ; 95 \% \mathrm{CI}=0.45-1.03)$ and a small reduction in risk for the temps levé $(\mathrm{RR}=0.72 ; 95 \% \mathrm{CI}=0.53-0.98)$. A $2^{\circ}$ greater pelvic angle on the left leg for the temps levé was associated with a decrease in injury risk $(R R=0.52$; $95 \% \mathrm{CI}=0.30-0.90$ ), and a $2^{\circ}$ greater fondu pelvic angle on the right leg was associated with an increase in injury risk (RR 1.28; 95\% CI 0.91-1.80) [38]. The incorrect 
technique of 'rolling in' was related to back injuries (OR 2.166; 95\% CI 1.124-4.174; $\quad P=0.021) \quad$ and non-categorised injuries (OR 2.707; 95\% CI 1.425-5.141; $P=0.002)$ in adolescent dancers [49].

\section{Meta-analysis}

Only two dance-specific screening measurements were eligible for meta-analysis: functional turnout ROM and compensated turnout ROM [24, 32]. Another study [28] also measured functional turnout but was not included in the meta-analysis due to lack of standard deviation values, and unfortunately, attempts at requesting the data from the author were unsuccessful. The pooled mean difference of compensated turnout was $23.29^{\circ}$ (95\% CI $14.85-$ 31.73; $\left.P<0.00001 ; I^{2}=0 \%\right)$ indicating injured dancers have a significantly higher compensated turnout measurement than non-injured dancers (Fig. 3). The pooled mean difference of functional turnout was $14.08^{\circ}$ (95\% CI 7.09-21.07; $\left.P<0.0001 ; I^{2}=0 \%\right)$ indicating that again injured dancers had significantly greater functional turnout measurements when compared to non-injured dancers (Fig. 4).

\section{Hypermobility}

Seven studies investigated the relationship between hypermobility and injury [37, 45-48, 59, 62]. One study included contemporary dancers [45], three studies included Irish dancers [46-48], two studies were unclear [59, 62] and one study included ballet dancers [37]. Three studies classified dancers as elite/professional [37, 48, 62], and two studies reported a mixed group of levels [46, 47]. One study classified dancers as non-elite/non-professional [45] and one study as pre-professional [59]. Four studies included dancers above 18 years old [45-48]. One study included dancers below 18 years old [59], and one study used dancers spanning the age range 17-25 years [62]. One study did not report the age [37], and all seven studies used both males and females [37, 45-48, 59, 62].

Six studies defined the injury [45-48, 59, 62], and one study did not define the injury [37]. Injury diagnosis was self-reported in six studies $[45-48,59,62]$ and unclear in one study [37]. Two studies used regression models or risk measurement $[46,47]$, and four studies used inferential analysis that did not include regression or risk measurements $[45,48,59,62]$ to determine which factors were associated with injury. The statistical analysis was unclear in one study [37].

Ruemper and Watkins [45] investigated students at a contemporary dance school and reported that 69\% of students had general joint hypermobility and 33\% had joint hypermobility syndrome. The total number of injuries $(r=.331 ; P=0.002)$, physical complaint injuries $(r=.249 ; P=0.022)$ and time loss injuries $(r=.352$; $P=0.001)$ were significantly correlated with the Brighton Criteria and joint hypermobility syndrome. McCormack et al. [37] investigated ballet dancers and reported that $47 \%$ of females (OR 6.75; 95\% CI $1.35-33.66$ ) and $37.5 \%$ of males (OR 7.8, 95\% CI 0.90-67.37) demonstrated benign joint hypermobility syndrome as measured by the Brighton Criteria in comparison with controls. In female dancers, $78 \%$ exhibited arthralgia which was associated with skin hyperextensibility, recurrent dislocation and multiple soft tissue injuries. Only $20 \%$ of the non-benign joint hypermobility syndrome dancers exhibited arthralgia. In male dancers, $83 \%$ of those with benign joint hypermobility syndrome and $70 \%$ of the non-benign joint hypermobility syndrome dancers complained of pain.

\section{Clinical Diagnostic Tests}

Six studies $[5,28,39,53,59,63]$ investigated the relationship between clinical diagnostic tests and injury and included orthopaedic testing of the foot, knee, ankle and hip [28], Thomas test [5], iliotibial band test [5, 59], anterior draw ankle $[39,53]$, Cumberland Ankle Instability [53], talar tilt [39] and knee joint stability [63]. Two studies included ballet dancers [28, 39], three studies were unclear $[5,59,63]$ and one study included mixed genre [53]. One study [28] contained dancers classified as elite/professional, three studies contained dancers classified as non-elite/non-professional [39, 53, 63] and in two studies, the level was pre-professional $[5,59]$. Five studies included dancers under 18 years old $[28,39,53$, $59,63]$, and one study considered 14-18-year-olds [5]. Two studies included females only [39, 63], and four studies were mixed $[5,28,53,59]$. Five studies defined the injury $[28,39,53,59,63]$, and one study did not provide a definition [5]. Injury diagnosis was provided by a physical therapist/physiotherapist or doctor in one study [28], was self-reported in four studies $[5,39,53,59]$ and

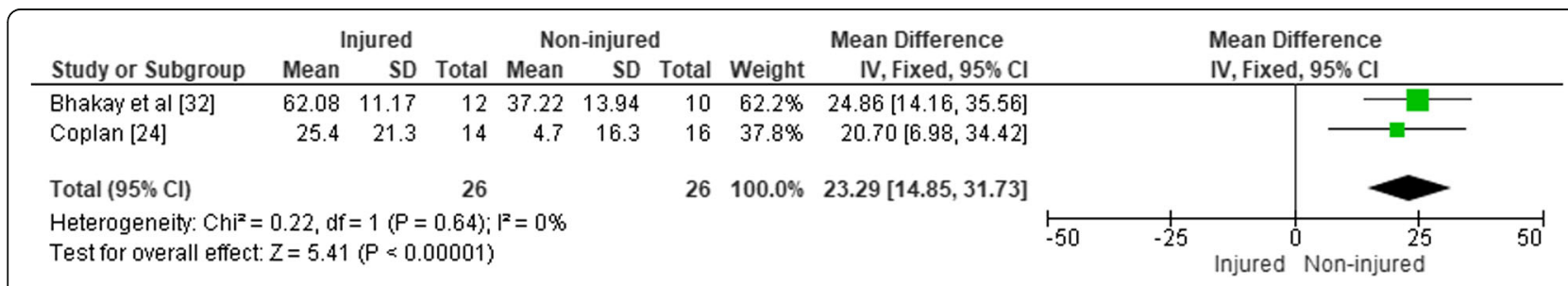

Fig. 3 Forest plot of the comparison of compensated turnout between injured and non-injured dancers 


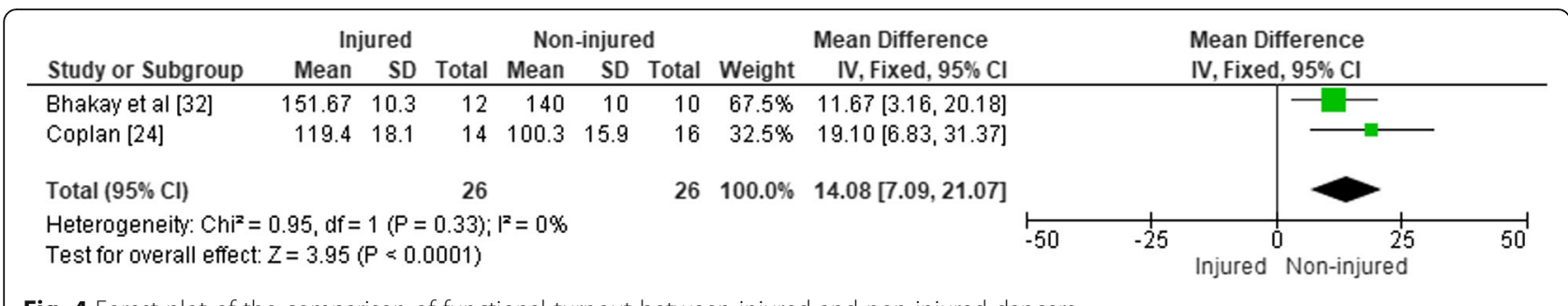

Fig. 4 Forest plot of the comparison of functional turnout between injured and non-injured dancers

unclear in one study [63]. One study used regression models or risk measurement [53], and three studies used inferential analysis that did not include regression or risk measurements $[5,39,59]$ to determine which factors have an association with injury. Two studies used both types of analysis [28, 63].

None of the studies reported significant findings for clinical screening tools.

\section{Movement Screening Tools}

Six studies investigated the relationship between movement screening tools and injury [27, 46-48, 56, 57]. These tools included the Functional Movement Screen [27, 48], Functional Movement Screen and Star Excursion Balance Test [46, 47], Y Balance Test [56] and Movement Competency Screen [57]. One study included ballet dancers [26], three studies involved Irish dancers [46-48], one study was unclear on genre [57] and one study used a mixed genre of dancers [56]. Two studies contained dancers classified as elite/professional [27, 48], two studies as pre-professional $[56,57]$ and two studies used a mixed level [46, 47]. Four studies used dancers above 18 years old [27, 46-48], and two studies used dancers that spanned the age ranges 16-24 years [57] and 17-30 years [56]. All six studies were mixed gender and provided a definition of injury with injury diagnosis self-reported in five studies [46-48, 56, 57]. Injury diagnosis was provided by a physiotherapist in one study [27]. Four studies used regression models or risk measurement $[46,47,56,57]$, and two studies used inferential analysis $[27,48]$ to determine which factors had an association with injury. All other findings on movement screening tools were non-significant.

Lee et al. [57] used the Movement Competency Screen to identify injuries prospectively in full-time pre-professional dancers and reported that those dancers with a Movement Competency Score $<23$ had an increased risk of injury $(P=0.035)$.

\section{Muscle Control, Strength, Power and Endurance}

Ten studies investigated the relationships between muscle control, strength, power and endurance and injury [26, 28, 29, 33, 52, 58-60, 62, 65]. Four studies included ballet dancers $[26,28,29,33]$, and in four studies genre was unclear [58-60, 62]. One study contained a mix of genres [52], and one study used dance degree students [65]. Five studies classified dancers as elite/ professional [26, 28, 29, 60, 62], two studies as non-elite/ non-professional $[52,65]$ and three studies as pre-professional $[33,58,59]$.

Three studies used dancers under 18 years old [26, 28, $59]$, five studies used dancers above 18 years old [29, 52, $58,60,65]$, one study [33] did not report the age and one study spanned the age range $17-25$ years [62]. Six studies were mixed gender $[28,29,58,59,62,65]$, three studies were female only $[26,52,60]$ and one study did not report the gender [33].

Five studies defined the injury $[28,52,58,59,62]$, but five studies did not define the injury [26, 29, 33, 60, 65]. Injury diagnosis was provided by a physical therapist/ physiotherapist or doctor in two studies [26, 28], self-reported in six studies $[29,52,58,59,62,65]$, diagnosed by a 'healthcare professional' in one study [60] and unclear in one study [33]. Four studies used regression models or risk measurement [52, 60, 62, 65], and four studies used inferential analysis that did not include regression or risk measurements $[26,29,58,59]$ to determine which factors have an association with injury. One study did not report statistical tests [33], and one study used both types of analysis [28].

Injured elite adolescent ballet dancers had lower extremity strength as measured by the mean score of 16 different lower limb tests than the non-injured dance group $(P=0.045)$ [28]. A significant negative correlation existed between the total number of days off due to injuries and standing vertical jump $(r=-0.66 ; P=0.014)$ [52]. It was reported that $30 \%$ of dancers without a history of low back pain were not able to perform a correct contraction of the transversus abdominus muscle compared to $63 \%$ of dancers with a history of low back pain $(P=0.048)$, and a significant difference existed for bent knee fall out on the left leg between dancers with and without a history of low back pain $(P=0.049)$ [59]. Lumbopelvic motor control was found to predict injuries in dancers, and it was reported that the knee lift abdominal test on the right side $(P=0.015)$ and the standing bow $(P=0.029)$ were predictors of injury. A standing bow and a low pressure increase during the knee lift 
abdominal test were a risk for the development of lower limb injuries [62].

\section{Other Screening Tools}

Ten studies $[5,28,33,46-48,52,56,59,60]$ investigated the relationship between other factors not appropriate for previous categories and injury. These included pain pressure threshold [46-48], number of jumps per $30 \mathrm{~s}$ [46-48], percentage maximum heart rate [46-48], vertical leap [46-48], Marshall Test [5], pain provocation test [59], Dance Aerobic Fitness Test [52, 60], heel balance [28], balance [48], one-leg standing test [56], unipedal dynamic balance [56] and ankle/foot risk [33]. Two studies included ballet dancers $[28,33]$, and three studies included Irish dancers [46-48]. In three studies, the genre was unclear $[5,59,60]$, and two studies contained a mix of genre $[52,56]$. Three studies contained dancers classified as elite/professional/full time $[28,48,60]$, four studies used dancers classified as pre-professional $[5,33,56,59]$, one study used non-elite/non-professional dancers [52] and two studies used mixed levels of dancers [46, 47]. Five studies used dancers above 18 years old [46-48, 52, 60], and one study used dancers below 18 years old [59]. Three studies used dancers spanning the age ranges 9-20 years [28], 14-18 years [5] and 17-30 years [56], and one study did not report the age [33]. Seven studies included mixed gender [5, 28, 46-48, 56, 59], two studies used female only $[52,60]$ and one study did not report the gender [33].

Seven studies defined the injury [28, 46-48, 52, 56, 59], and three studies did not define the injury $[5,33,60]$. Injury diagnosis was self-reported in seven studies $[5,46-$ $48,52,56,59]$, not reported in one study [33], made by a 'healthcare professional' in one study [60] and was diagnosed by a physical therapist/physiotherapist or doctor in one study [28]. Five studies used regression models or risk measurement $[46,47,52,56,60]$, and three studies used inferential analysis that did not include regression or risk measurements $[5,48,59]$. One study did not report the type of statistical analysis [33], and one study used both types of analysis [28].

There was a significant correlation $(r=.590 ; P=0.034)$ between the number of injuries sustained and heart rate observed at the end of the Dance Aerobic Fitness Test [60]. All other findings were reported at the non-significant level.

\section{Discussion}

To the best of our knowledge, this is the first systematic literature review and meta-analysis to investigate which screening tools can predict injury in all genres, levels and ages of dancers.

\section{Methodological Quality}

The mean score using the methodological quality tool was 12.2 points (range $6-17$ points) with all studies being of level 4 evidence. Four studies [33, 34, 40, 51] did not provide a description of the screening tools used. As with many injury studies, the literature is limited by the varying definitions of musculoskeletal injury and by who defined the injury. Twenty-five studies $[24,27,28,30-$ $32,38,39,44-48,50-59,62,63$ ] provided a definition of musculoskeletal injury, but these lacked consistency in the definition. Furthermore, in only eight studies [26$28,38,44,49,55,64]$, the diagnosis was made by either a physical therapist/physiotherapist or doctor. Only five studies defined the injury and had the diagnosis made by a physical therapist/physiotherapist or doctor $[27,28,38$, $44,55]$. As a minimum, it is recommended that studies should provide a definition of musculoskeletal injury and have the diagnosis made by a medical professional ideally a physical therapist/physiotherapist or doctor. The reporting of the reliability of the screening tools used is important and was reported in 13 studies [30, 31, 41$43,47,49,53,57,62-65]$, but only six studies [30, 31, 43, $57,62,63]$ assessed the reliability within their own study.

\section{Range of Motion}

A number of studies reported significant findings between ROM and injury; however, these findings were across a number of locations and comparison included different/missing musculoskeletal injury definitions, measurements taken, mix of genres, levels and ages of dancers. For those studies that demonstrated significant findings for the hip ROM, four studies used inferential analysis that did not include regression or risk measurements to identify injury $[26,32,35,58]$. Hamilton et al. [26] reported unequal hip motion in 'minor injured' dancers; however, testing reliability was not reported. Hip hyperabduction was related to foot or ankle tendinopathies [49]; hip abduction, internal rotation and lower back/hamstring flexibility were associated with PFPS; hip abduction was a predictor of knee, foot and non-categorised injuries [63]. Asymmetric hip internal rotation was associated with prior injury [58], and straight leg raise ROM was increased in male ballet dancers with four or more past injuries [29]. Total hip external rotation was related to the injury in one study [32]. However, the meta-analysis [24, 39] demonstrated no significant difference in passive external hip rotation between injured and non-injured groups. The relationship between greater mean pain intensity scores and sacrum inclination angle [35] is limited by no comparative studies and the complex relationship between pain and injury.

At the knee, significant findings were limited to a correlation between left popliteal angle and injury [5]; 
however, injury was self-reported, and no injury definition was provided. Greater patella mobility in PFPS dancers existed compared to a control group [63]. Dancers identified as 'drop outs' had a minus recurvatum and 'straight legs' [26]; however, the reason for 'drop out' may not necessarily have been injury. There was a lack of consistency in the findings at the ankle with increased passive inversion [53], decreased left dorsiflexion [29], right pronation and insufficient right plantarflexion [28] all related to injury. Steinberg et al. [63] stated greater ankle dorsiflexion and hindfoot varum in dancers with PFPS, and ankle plantarflexion was a predictor of knee, back and non-categorised injuries. However, this study used age- and gender-matched dancers with and without PFPS which limits the comparison with studies of non-matched design. Limited ankle dorsiflexion during a single-leg squat was found to be a risk factor for substantial lower extremity injury [65]; however, measurement was in weight-bearing only, and no injury definition was provided. At the upper limb, significant findings were limited to increased elbow extension in male ballet dancers with four or more past injuries [29]; however, no specific information was provided regarding injury location or limb dominance. Due to the inconsistency of the results, it is unclear if $\mathrm{ROM}$ is a significant predictor of injury in dancers.

\section{Anthropometric and Posture}

Limited positive findings existed between anthropometric measurements, posture and injury. A higher incidence of spondylolisthesis in ballet students who 'dropped out' the profession [26] may not relate to injury as for whether injury was a factor in 'drop out' was not reported in sufficient detail. Scoliosis was related to injury in young dancers aged 8-16 years [49] and was a predictor of PFPS in 15- 16-year-olds [63]. Scoliotic dancers aged 8 to 16 years had more total injuries, and back injuries were more prevalent [64]. In adolescent dancers, a change in right foot length was reported to be associated with increased injury risk [38]. Adolescents are subject to growth spurts and these changes may influence injury prevalence, and such age-specific findings require further investigation. The role of body type in injury was unclear in the included studies. An ankle injury may be associated with endomorphy and foot injury with ectomorphy [31]. Ectomorphy was a predictor of acute injuries whilst mesomorphy was negatively correlated with the number of overuse injuries [36]. Body fat was negatively associated with 'time modifying activity' [60], a term that does not necessarily equate to injury. Stress fractures were associated with below ideal weight [40]; however, this was one of the lowest scoring studies (7 points), so the methodological quality can be questioned. Left thigh circumference was larger in injured
11- to 12-year-old dancers compared to non-injured dancers of the same age [61]. One study reported a significant relationship between 'pain' and body mass index [35], but it is difficult to equate pain directly to the musculoskeletal injury. Due to the inconsistency of the results, it is unclear if anthropometric measures and posture are a significant predictor of injury in dancers.

\section{Dance-Specific Positions}

The functional element of dance-specific position measurement is of potential value, and a number of significant findings were reported. Hamilton et al. [26] reported a lack of turnout demonstrated in an asymmetrical plié and pronation when landing from sauté in injured dancers; however, interpretation is limited by the use of the term 'minor injured' as no clear definition was provided. Functional and compensated turnout was greater in injured than non-injured ballet dancers [24], and an increase in compensated turnout and muscular value ratio was both predictors of increased injury [44]. Negus et al. [30] reported that the number of non-traumatic injuries was positively correlated with six derived turnout variables and non-traumatic injury severity with three derived turnout variables. Compensated turnout was related to injury in female professional ballet dancers [32] and to having more than one injury and low back pain [54]; however, both studies failed to report the reliability of screening. The incorrect technique of 'rolling in' and associated pronation with the patella above or medial to the first toe was related to back injuries and non-categorised injuries in adolescent dancers and may relate to trying to achieve the optimum turnout position [49]. The temps levé and fondu knee and pelvic angle were associated with injury risk in elite adolescent ballet dancers [38]. The meta-analysis provided stronger evidence that both compensated turnout and functional turnout measurements are significantly different between injured and non-injured dancers. Overall, the evidence in this review suggests that turnout measures may have the potential to be used in the identification of dancers at risk of injury.

\section{Hypermobility}

Despite the use of recognised screening tools in the form of the Beighton Score and Brighton Criteria, limited evidence existed regarding the relationship between hypermobility and dance injury. A total number of injuries, physical complaint injuries and time loss injuries was significantly correlated with the Brighton Criteria and joint hypermobility syndrome, but no relationship existed between injury and general joint hypermobility assesses via the Beighton Score [45]. McCormack et al. [37] reported increased arthralgia in dancers with benign joint hypermobility syndrome in comparison with those without the syndrome. The methodology of this study was limited with 
information regarding the diagnosis and definition of injury not provided. Studies that investigate hypermobility should use the Beighton Score to define joint hypermobility and consider recent research [66] which has suggested a new spectrum of hypermobility disorders which requires investigation in dance. Due to the inconsistency of results, it is unclear if hypermobility is a significant predictor of injury in dancers.

\section{Clinical Diagnostic Tests}

No significant findings were reported for clinical diagnostic tests, and therefore currently, it appears that clinical diagnostic tests are not a significant predictor of injury in dance.

\section{Movement Screening Tools}

Only one study reported a significant relationship between movement screening tools and injury with the suggestion that pre-professional dancers with a Movement Competency Screen score of $<23$ had an increased risk of injury [57]. However, this screening tool is relatively new, and future research with dancers is required. Analysis of studies that used the Functional Movement Screen was limited by the failure to use all the seven movements of the screen in three studies [46-48]. Interpretation of the Star Excursion Balance Test is limited to the movement in a posteromedial direction [46-48]. Therefore, it is unclear if movement screening tools are a useful predictor of dance injury.

\section{Muscle Control, Strength, Power and Endurance}

Minimal positive findings existed within the domain of muscle strength and power with study comparison limited due to differing methods. Lower extremity strength, determined by the mean of 16 lower limb tests, was lower in injured dancers [28]; however, this study failed to consider the relative contribution of each element. Standing vertical jump as a measurement of power was negatively correlated with a total number of days off due to injuries [52]; however, injury was recorded retrospectively and via self-reporting questionnaire and therefore potentially open to recall bias. An inability to perform a correct contraction of the transversus abdominus in dancers with a history of low back pain was reported [59], and positive standing bow and a low pressure increase using a pressure biofeedback unit during right side knee abdominal lift test were found to predict injury [62]. However, limited research exists using the standing bow and knee abdominal lift test, and therefore, future research is required. No significant relationships were found between muscle endurance and injury. Due to the inconsistency of results, it is unclear if muscle control, strength and power are a significant predictor of injury in dancers.

\section{Other Screening Tools}

Findings were limited to a significant correlation between a number of injuries sustained and heart rate observed at the end of the Dance Aerobic Fitness Test [60]. The variety of 'other screening tools' and limited findings suggest that it is unlikely that these screening tools predict injury. However, the positive finding for heart rate [60] requires further investigation.

\section{Limitations}

Only three measurements were eligible for further analysis via a meta-analysis, namely passive hip external rotation ROM [24, 39], functional turnout ROM [24, 32] and compensated turnout ROM [24, 32]. Identification of which musculoskeletal screening tools may predict injury proved difficult due to the lack of standardisation of methods and reporting of data. The authors hoped to perform a meta-analysis of a number of measurements; however, this was prevented by poor reporting of methodology and variation in the measurement of parameters. Furthermore, the included literature was limited by small sample size, contrasting injury surveillance methods and risk factor identification and failure to consider confounding variables. Some studies focussed on the identification of one specific type of injury, and therefore, when contrasting these studies, care should be taken. It is also important to consider that many dancers continue to dance when injured, and although they may have pain, they may not necessarily be injured. Pain can result in dance movement modification, and this potentially could be considered in future studies. Hence, identification of which musculoskeletal screening tools may predict injury is currently difficult.

This study has provided information regarding the different genres, level of dance and ages of a dancer as all may influence the outcome of the study. Incomplete description of dancer demographics [31-33, 37, 51], inclusion/exclusion criteria $[5,24,26-28,31,33,34,37,38$, $40,43,45,49,51,52,54,55,57,59,60,62,64]$ and reporting of dropouts was present in a number of studies $[5,24,26-28,30-33,35-37,39-46,49-52,54,55$, 60-64] which can hinder the interpretation. The lack of reported consideration of confounding variables in the study is concerning and may impact of the interpretation of results. The reliability of screening tools requires greater consideration as an unreliable tool may result in a lack of consistency in measures. Furthermore, there is a need for the average weekly dance rehearsal load to be reported to allow calculation of injury rate and exposure data as this may impact on injury rate. Information regarding performance rate, position in the company, floor surface and time point in the season are all factors that may require consideration, and studies should report the injury severity and injury duration and define the injury. 
The authors felt it was important to provide information on both the diagnosis and definition of injury and as such included this in the methodological scoring, as a lack of homogeneity in studies makes a comparison of incident rates and risk factors difficult. The validity and reliability of screening tools should be reported to allow determination of internal validity and inter-rater and intra-rater reliability as appropriate, and for those tools that have not had these factors determined with dancers, pilot testing is required. Studies should report their own within-study reliability. Prospective injury cohort studies are preferential in comparison with retrospective studies, and power calculations are advocated to determine sample size. Future research should consider multivariate regression models if the aim is to determine the predictors of injury and if considering multiple risk factors should control for confounding variables and consider the potential interaction of those measures that are screened. Overall, only two studies [38, 44] provided the following: (i) prospective design, (ii) an injury definition, (iii) a diagnosis by a physical therapist/physiotherapist or doctor and (iv) the use of regression models or risk measurement. These four factors could be considered good practice in investigating screening tools as a predictor of injury, and the paucity of studies that meet these requirements highlights the need for future research.

This systematic review and meta-analysis is the first to collate and critically appraise musculoskeletal screening tools as a predictor of injury across all dance levels, genres and ages. The reporting of all components of the review process allows the results to be replicated with an effective scoring tool that recognises the importance of key factors including injury reporting and reliability. Some limitations existed as the authors restricted their search to articles that were English language studies, and therefore potentially, some studies may not have been included.

\section{Conclusions}

Evidence exists for the potential use of dance-specific positions as a predictor of injury with the meta-analysis providing evidence for the use of functional turnout and compensated turnout ROM. However, such movements are ballet specific and therefore potentially not relevant to other dance genres. Some evidence existed for measurement of hip ROM within the systematic review; however, this was not supported by the meta-analysis. The evidence for hypermobility as a screening tool is inconsistent, and there is a need to consider both the Beighton Score and the recently amended hypermobility spectrum [66]. There is a lack of studies that have utilised movement screening tools such as the Functional Movement Screen and Star Excursion Balance Test. Future studies that investigate the ability of screening tools to predict injury should be prospective, use predictive statistics, report the reliability of the tests and consider confounders. A specific definition of injury should be provided and diagnosis provided by an appropriate medical professional.

\section{Abbreviations}

Cl: Confidence interval; OR: Odds ratio; PFPS: Patellofemoral pain syndrome; ROM: Range of motion; RR: Relative risk

\section{Acknowledgements \\ The authors wish to thank Dr. Joan Dallinga for the information provided regarding the scoring tool. \\ Funding \\ The authors wish to thank the Edge Hill University Open Access Fund who provided funding.}

\section{Availability of Data and Materials}

Data presented in the meta-analysis of this article is available in the associated studies, references are provided.

\section{Authors' Contributions}

RA produced the original idea and conducted the literature search. He also reviewed and scored the returned articles. He performed the meta-analysis and wrote the manuscript. NR reviewed and scored the returned articles. She performed the meta-analysis and assisted with the writing of the manuscript. Both authors read and approved the final manuscript.

\section{Authors' Information}

Ross Armstrong is a Chartered Physiotherapist with 18 years of experience specialising in musculoskeletal physiotherapy. He is a lecturer in Sports Therapy and holds a MSc Sports and Exercise Medicine and has published within the domain of Dance and Exercise Medicine. He is a Cochrane-trained review author.

Dr. Nicola Relph is a specialist in biomechanics and senior lecturer in Epidemiology and has published a systematic review and meta-analysis previously. She is a Cochrane-trained review author.

\section{Ethics Approval and Consent to Participate}

Ethical approval was not required for this systematic review and meta-analysis.

\section{Consent for Publication}

Not applicable as this manuscript does not include any individual person's data.

\section{Competing Interests}

The authors, Ross Armstrong and Nicola Relph, declare that they have no competing interests.

\section{Publisher's Note}

Springer Nature remains neutral with regard to jurisdictional claims in published maps and institutional affiliations.

\section{Author details \\ ${ }^{1}$ Sports Injuries Research Group, Department of Sport and Physical Activity, Edge Hill University, Ormskirk, Lancashire L39 4QP, England. 'Faculty of Health and Social Care, Edge Hill University, Ormskirk, Lancashire L39 4QP, England.}

Received: 27 March 2018 Accepted: 2 July 2018

Published online: 18 July 2018

\section{References}

1. Simon J, Hall E, Docherty C. Prevalence of chronic ankle instability and associated symptoms in university dance majors an exploratory study. J Dance Med Sci. 2014;18(4):178-84. https://doi.org/10.12678/1089-313X.18.4.178.

2. Ricard MD, Veatch $S$. Effect of running speed and aerobic dance jump height on vertical ground reaction forces. J Appl Biomech. 1994;10(1):14-27. 
3. Rousanoglou EN, Boudolos KD. Ground reaction forces and heart rate profile of aerobic dance instructors during a low and high impact exercise programme. J Sports Med Phys Fitness. 2005;45(2):162-70.

4. Brogden CM, Armstrong R, Page R, Milner D, Norris D, Greig M. Use of triaxial accelerometry during the Dance Aerobic Fitness Test: considerations for unit positioning and implications for injury and performance. J Dance Med Sci. 2017; In press

5. Luke A, Kinney S, D'Hemecourt PA, Baum J, Owen M, Micheli L. Determinants of injuries in young dancers. Med Probl Perform Art. 2002;17:105-12.

6. Gamboa JM, Roberts $L A$, Maring J, Fergus A. Injury patterns in elite preprofessional ballet dancers and the utility of screening programs to identify risk characteristics. J Orthop Sports Phys Ther. 2008;38:126-36.

7. Nilsson C, Leanderson J, Wykman A, Strender LE. The injury panorama in Swedish professional ballet company. Knee Surg Sports Traumatol Arthrosc. 2001;9:242-6. https://doi.org/10.1007/s001670100195

8. Ekegren $\mathrm{CL}$, Quested R, Brodrick A. Injuries in pre-professional ballet dancers: incidence, characteristics and consequences. J Sci Med Sport. 2014;17(3):271-5.

9. Hincapie CA, Morton EJ, Cassidy JD. Musculoskeletal injuries and pain in dancers: a systematic review. Arch Phys Med Rehabil. 2008;89:1819-29.

10. Jacobs C, Hincapie CA, Cassidy JD. Musculoskeletal injuries and pain in dancers: a systematic review update. J Dance Med Sci. 2012;16:74-84.

11. Fietzer A, Chang Y, Kulig K. Dancers with patellar tendinopathy exhibit higher vertical and braking ground reaction forces during landing. J Sports Sci. 2012:30:1157-63.

12. Gabbe BJ, Bennell KL, Wajswelner H, Finch CF. Reliability of common lower extremity musculoskeletal screening tests. Phys Ther Sport. 2004;5(2):90-7.

13. Dennis RJ, Finch CF, Elliott BC, Farhart PJ. The reliability of musculoskeletal screening tests used in cricket. Phys Ther Sport. 2008;9(1):25-33.

14. Chorba R, Chorba DJ, Bouillon LE, Overmyer CA, Landis JA. Use of a functional movement screening tool to determine injury risk in female collegiate athletes. N Am J Sports Phys Ther. 2010;5(2):47-54.

15. Kiesel KB, Butler RJ, Plisky PJ. Prediction of injury by limited and asymmetrical fundamental movement patterns in American football players. J Sport Rehabil. 2014;23(2):88-94. https://doi.org/10.1123/jsr.2012-0130.

16. Armstrong R. Functional movement screening as a predictor of injury in male and female rugby union players. Physiotherapy. 2016;102(supplement 1):e178-9.

17. Cook G, Burton L, Hoogenboom B. Pre-participation screening: the use of fundamental movements as an assessment of function - part 1. N Am J Sports Phys Ther. 2006;1 (2):62-72.

18. Cook G, Burton L, Hoogenboom B. Pre-participation screening: the use of fundamental movements as an assessment of function-part 2. N Am J Sports Phys Ther. 2006b;1(3):132-9.

19. Gray G. Lower extremity functional profile. Adrian: Wynn Marketing; 1995.

20. Beighton P, Solomon L, Soskolne CL. Articular mobility in an African population. Ann Rheum Dis. 1973;32:413-8.

21. Van Mechelen W, Hlobil H, Kemper H. Incidence, severity, aetiology and prevention of sports injuries. Sports Med. 1992;14:82-9.

22. Dallinga JM, Benjaminse A, Lemmink APM. Which screening tools can predict injury to the lower extremities in team sports? a systematic review. Sports Med. 2012;42(9):791-815.

23. Devillé WL, Buntinx F, Bouter LM, Montori VM, de Vet HCW, van der Windt DAWM, et al. Conducting systematic reviews of diagnostic studies: didactic guidelines. BMC Med Res Methodol. 2002;3:2-9.

24. Coplan J. Ballet dancer's turnout and its relationship to self-reported injury. J Orthop Sports Phys Ther. 2002;32(11):579-84. https://doi.org/10.2519/jospt. 2002.32.11.579.

25. Deeks JJ, Higgins JPT, Altmsn DG. Chapter 9: analysing data and undertaking meta-analyses. In: Green S, editor. Cochrane Handbook for Systematic Reviews of Interventions version 5.1.0 [updated March 2011]: The Cochrane Collaboration; 2011. Available from http://www.handbook.cochrane.org.

26. Hamilton LH, Hamilton WG, Warren MP, Keller K, Molnar M. Factors contributing to the attrition rate in elite ballet students. J Dance Med Sci. 1997;1(4):131-8.

27. Allen N, Nevill AM, Brooks JHM, Koutedakis Y, Wyon MA. The effect of a comprehensive injury audit program on injury incidence in ballet: a 3-year prospective study. Clin J Sports Med. 2013;23(5):373-8. https://doi.org/10. 1097/JSM.0b013e3182887f32.

28. Gamboa J, Roberts L, Maring J, Fergus A. Injury patterns in elite preprofessional ballet dancers and the utility of screening programs to identify risk characteristics. J Orthop Sports Phys Ther. 2008:38(3):126-36. https://doi.org/10.2519/jospt.2008.2390.
29. Hamilton WG, Hamilton LH, Marshall P, Molnar M. A profile of the musculoskeletal characteristics of elite professional ballet dancers. Am J Sports Med. 1992;20(3):267-73. https://doi.org/10.1177/ 036354659202000306 .

30. Negus V, Hopper D, Briffa N. Associations between turnout and lower extremity injuries in classical ballet dancers. J Orthop Sports Phys Ther. 2005;35(5):307-18. https://doi.org/10.2519/jospt.2005.1600.

31. Zaletel P, Sekulić D, Zenić N, Esco MR, Šajber D, Kondrič M. The association between body-built and injury occurrence in pre-professional ballet dancers—-separated analysis for the injured body-locations. Int Journal Occup Med Environ Health. 2017;30(1):151-9. https://doi.org/10.13075/ijomeh. 1896.00818.

32. Bhakay M, Waghwani V, Kaur A. Relationship between ballet dancer turnout and self-reported lower limb injuries. Indian J Physiother Occup Ther. 2016;10(3):151-6. https://doi.org/10.5958/0973-5674.2016. 00100.3.

33. Wong R, Beasley A, Hessleton K, Maier A, Gamboa J, Roberts L. Predisposing factors to foot and ankle injuries in adolescent preprofessional ballet dancers. J Orthop Sports Phys Ther. 2008:38(1):A55.

34. Thomas JJ, Keel PK, Heatherton TF. Disordered eating and injuries among adolescent ballet dancers. Eating Weight Disord. 2011;16(3):e216-22. https:// doi.org/10.1007/BF03325136.

35. Drężewska M, Śliwiński Z. Lumbosacral pain in ballet school students. Pilot study. Ortop Traumatol Rehabil. 2013;15(2):149-58. https://doi.org/10.5604/ 15093492.1041451

36. Twitchett E, Angioi M, Metsios G, Koutedakis Y, Wyon M. Body composition and ballet injuries a preliminary study. Med Probl Perform Art. 2008;23(3):93-8.

37. McCormack M, Briggs J, Hakim A, Grahame R. Injury and benign joint hypermobility syndrome in student classical ballet dancers. Rheumatology. 2002:41:54.

38. Bowerman E, Whatman C, Harris N, Bradshaw E, Karin J. Are maturation, growth and lower extremity alignment associated with overuse injury in elite adolescent ballet dancers? Phys Ther Sport. 2014;15(4):234-41. https:// doi.org/10.1016/j.ptsp.2013.12.014.

39. Lin C, Lee I, Liao J, Wu H, Su F. Comparison of postural stability between injured and uninjured ballet dancers. Am J Sports Med. 2011;39(6):1324-31. https://doi.org/10.1177/0363546510393943.

40. Frusztajer NT, Dhuper S, Warren MP, Brooks-Gunn J, Fox RP. Nutrition and the incidence of stress fractures in ballet dancers. Am J Clinical Nutr. 1990; 51(5):779-83.

41. Watkins A, AP W-MN, Clarkson PM, Ebbeling C. Lower extremity alignment and injury in young, preprofessional, college and professional ballet dancers: part 1. Turnout and knee-foot alignment. Med Probl Perform Art. 1999;4(4):148-53.

42. McNeal AP, Watkins A, Clarkson PM, Tremblay I. Lower extremity alignment and injury in young, preprofessional, college and professional ballet dancers. Part II: dancer-reported injuries. Med Probl Perform Art. 1990;5(2):83-8.

43. Reid DC, Burnham RS, Saboe LA, Kushner SF. Lower extremity flexibility patterns in classical ballet dancers and their correlation to lateral hip and knee injuries. Am J Sports Med. 1987;15(4):347-52.

44. Baker-Jenkins JB, Wyon M, Nevill A. Can turnout measurements be used to predict physiotherapist-reported injury rates in dancers? Med Probl Perform Art. 2013;28(4):230-5.

45. Ruemper A, Watkins K. Correlations between general joint hypermobility and joint hypermobility syndrome and injury in contemporary dance students. J Dance Med Sci. 2012;16(4):161-6.

46. Cahalan R. A cross-sectional study of elite adult Irish dancers: biopsychosocial traits, pain, and injury. J Dance Med Sci. 2015;19(1):31-43. https://doi.org/10. 12678/1089-313X.19.1.31

47. Cahalan R, O'Sullivan P, Purtill H, Bargary N, Ni Bhriain O, O'Sullivan K. Inability to perform because of pain/injury in elite adult lrish dance: a prospective investigation of contributing factors: pain/injury lrish dance-a prospective study. Scand J Medicine Sci. 2016;26(6):694-702. https://doi.org/ 10.1111/sms.12492.

48. Cahalan R, Purtill H, O'Sullivan K. Biopsychosocial factors associated with foot and ankle pain and injury in Irish dance: a prospective study. Med Probl Perform Art. 2017;32(2):111-7.

49. Steinberg N, Siev-Ner I, Peleg S, Dar G, Masharawi Y, Zeev A, Hershkovitz I. Extrinsic and intrinsic risk factors associated with injuries in young dancers aged 8-16 years. J Sports Sci. 2012;30(5):485-95. https://doi.org/10.1080/ 02640414.2011.647705 
50. Jacobs CL, Cassidy JD, Côté P, Boyle E, Ramel E, Ammendolia C, Hartvigsen J, Schwartz I. Musculoskeletal injury in professional dancers: prevalence and associated factors. Clin J Sports Med. 2016;27(2):153-60. https://doi.org/10. 1097/JSM.0000000000000314.

51. Martin DF, Wiesler ER, Hunter DM, Curl WW, Batson G, Hoen H. Ankle flexibility and injury patterns in dancers. South Med J. 1996;89(10):95.

52. Angioi M, Metsios G, Koutedakis $Y$, Twitchett $E$, Wyon M. Physical fitness and severity of injuries in contemporary dance. Med Probl Perform Art. 2009; 24(1):26-9.

53. Hiller CE, Refshauge KM, Herbert RD, Kilbreath SL. Intrinsic predictors of lateral ankle sprain in adolescent dancers: a prospective cohort study. Clin J Sports Med. 2008;18(1):44-8. https://doi.org/10.1097/JSM.0b013e31815f2b35.

54. van Merkensteijn GG, Quin EQ. Assessment of compensated turnout characteristics and their relationship to injuries in university level modern dancers. J Dance Med Sci. 2015;19(2):57-62. https://doi.org/10.12678/1089313X.19.2.57.

55. Wiesler ER, Hunter DM, Martin DF, Curl WW, Hoen H. Ankle flexibility and injury patterns in dancers. Am J Sports Med. 1996;24(6):754-7.

56. Kenny SJ, Palacios-Derflingher L, Shi Q, Whittaker JL, Emery C. Association between previous injury and risk factors for future injury in preprofessional ballet and contemporary dancers. Clin J Sports Med. 2017. In press; https:// doi.org/10.1097/JSM.0000000000000513.

57. Lee L, Reid D, Cadwell J, Palmer P. Injury incidence, dance exposure and the use of the movement competency screen (MCS) to identify variables associated with injury in full-time pre-professional dancers. Int J Sports Phys Ther. 2017:2(3):352-70.

58. Davenport KL, Air M, Grierson MJ, Krabak BJ. Examination of static and dynamic core strength and rates of reported dance related injury in collegiate dancers: a cross-sectional study. J Dance Med Sci. 2016;20(4):15161. https://doi.org/10.12678/1089-313X.20.4.151.

59. Roussel N, De Kooning M, Schutt A, Mottram S, Truijen S, Nijs J, Daenen L. Motor control and low back pain in dancers. Int J Sports Med. 2013;34(2): 138-43. https://doi.org/10.1055/s-0032-1321722.

60. Twitchett E, Brodrick A, Nevill AM, Koutedakis Y, Angioi M, Wyon M. Does physical fitness affect injury occurrence and time loss due to injury in elite vocational ballet students? J Dance Med Sci. 2010;14(1):26-31.

61. Steinberg N, Aujla I, Zeev A, Redding E. Injuries among talented young dancers: findings from the UK centres for advanced training. Int J Sports Med. 2014;35(3):238-44. https://doi.org/10.1055/s-0033-1349843.

62. Roussel NA, Nijs J, Mottram S, Van Moorsel A, Truijen S, Stassijns G. Altered lumbopelvic movement control but not generalized joint hypermobility is associated with increased injury in dancers. A prospective study. Manual Ther. 2009;14(6):630-5. https://doi.org/10.1016/j.math.2008.12.004.

63. Steinberg N, Tenenbaum S, Hershkovitz I, Zeev A, Siev-Ner I. Lower extremity and spine characteristics in young dancers with and without patellofemoral pain. Res Sports Med. 2017;25(2):166-80. https://doi.org/10. 1080/15438627.2017.1282355

64. Steinberg N, Hershkovitz I, Peleg S, Dar G, Masharawi Y, Zeev A, Siev-Ner I. Morphological characteristics of the young scoliotic dancer. Phys Ther Sport. 2013;14:213-20.

65. van Seters C, van Rijn RM, van Middelkoop M, Stubbe JH. Risk factors for lower-extremity injuries among contemporary dance students. Clin J Sports Med. 2017. In press; https://doi.org/10.1097/JSM.0000000000000533.

66. Castori M, Tinkle B, Levy H, Grahame R, Malfait F, Hakim A. A framework for the classification of joint hypermobility and related conditions. Am J Med Genet. 2017;175C:148-57.

\section{Submit your manuscript to a SpringerOpen ${ }^{\circ}$ journal and benefit from:}

- Convenient online submission

- Rigorous peer review

- Open access: articles freely available online

- High visibility within the field

- Retaining the copyright to your article

Submit your next manuscript at $\gg$ springeropen.com 